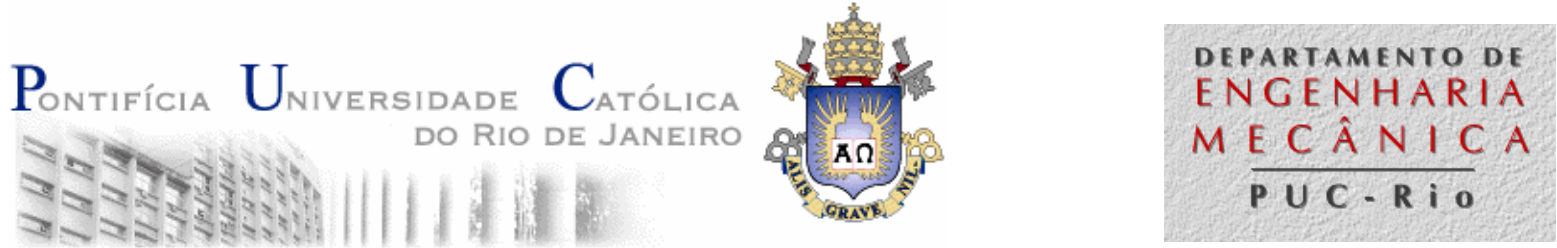

Projeto de Graduação 2006.2

\title{
CALIBRAÇÃO DE UM MEDIDOR DE EMISSIVIDADE COM A UTILIZAÇÃO DO TERMOVISOR.
}

\author{
Aluno: \\ Bruno Severino \\ bruno_seve@hotmail.com \\ Orientador: \\ Alcir de Faro Orlando \\ afo@mec.puc-rio.br
}




\section{Resumo}

O presente estudo dá continuidade à [1], que visa determinar a calibração do coeficiente de troca de calor experimentalmente através da medida de emissividade com auxilio do termovisor de uma superfície através de duas cascas cilíndricas concêntricas. A casca cilíndrica interna é aquecida com o uso de resistências e através do fluxo de energia entre os cilindros obtivemos o valor da emissividade.

A emissividade é um fator que indica a eficiência de uma superfície em emitir energia, quando comparada com um corpo negro à mesma temperatura. $\mathrm{O}$ conhecimento da emissividade é um pré-requisito imprescindível na caracterização de materiais a partir da análise de imagens térmicas, como também na estimativa de temperaturas de superfícies obtidas a partir de dados sensoriados no infravermelho termal. De uma maneira geral, as emitâncias variam com a composição física, química e biológica das superfícies.

Os processos térmicos de medida se baseiam na medida da transferência de calor entre duas superfícies, com emissividade a ser calculada a partir das equações de balanço térmico. Os valores experimentalmente encontrados serão comparados com o valores achados em [1]. Diversos testes foram realizados e a eles aplicados processos de análise de incerteza. 


\section{Abstract}

The emissivity is a factor that indicates the efficiency of a surface to emit energy, when compared with a black body in the same temperature. The knowledge of emissivity is a essential requisite on CARACTERIZAÇÃO of materials starting by thermal images, also to estimate of temperatures of surfaces gotten from data in the thermal infrared. Most of the times, the emissivity changes with physical, chemical and biological composition.

The thermal processes of measurement are based on the measure of heat transfer between two surfaces, with the emissivity that will be calculated through thermal balance equations. The experimental value founded will be compared with value founded in [1].Several tests have been performed and obtained an uncertainly analysis process. 


\section{Agradecimentos}

Ao professor orientador Alcir de Faro Orlando pela oportunidade de desenvolvimento do tema e pelos conhecimentos compartilhados.

Ao engenheiro Marlon Huamani pelo apoio e ajuda nas soluções dos problemas acontecidos.

Aos técnicos João Peixe e Evemero Callegari e ao auxiliar técnico Marcelo Oliveira pela dedicação e idealização na instrumentação do experimento.

À PUC-Rio pela disponibilidade dos laboratórios utilizados.

Aos meus amigos e familiares pelo apoio constante.

Aos meus pais e meus avós, responsáveis por tudo na minha formação.

À Deus. 


\section{Índice}

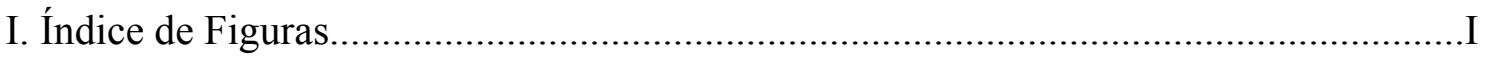

II. Índice de Equações.....................................................................................................

III. Índice de Tabelas...............................................................................................II

1. Introdução

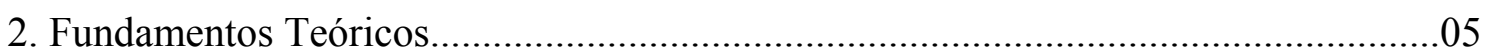

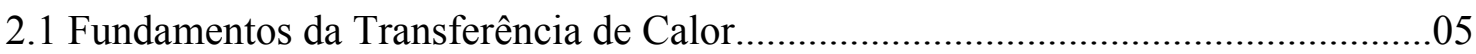

2.2 Calibração de termômetros infravermelhos no Brasil...................................................14

2.3 Modelo Teórica para a medição da emissividade.......................................................20

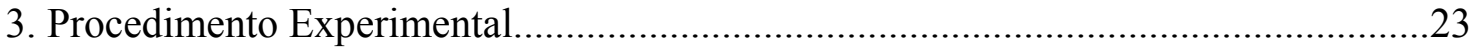

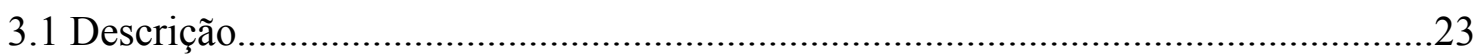

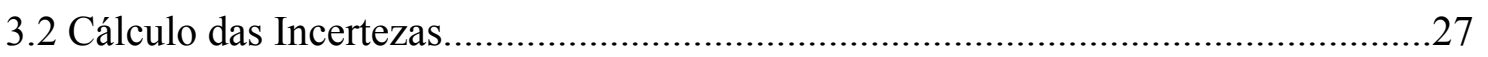

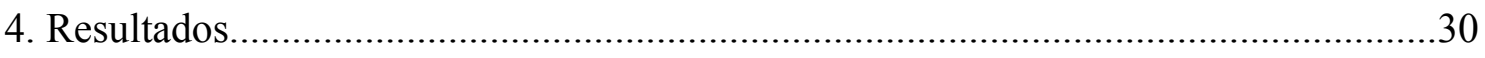

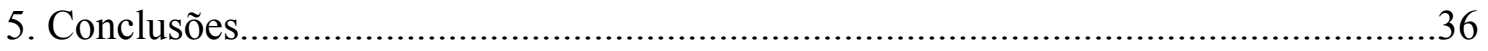

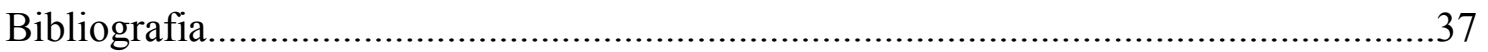

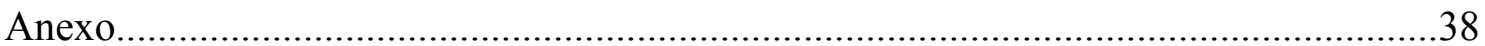




\section{Índice de Figuras}

Figura 1 : Emitância espectral de corpo negro para 5 temperaturas, $\log \mathrm{x} \log \ldots \ldots \ldots \ldots \ldots . . . . .06$

Figura 2 : Emissividade em corpos negros, cinzentos e reais (qualitativo).....................07

Figura 3 : Desenho esquemático da calibração de pirômetro infravermelho....................18

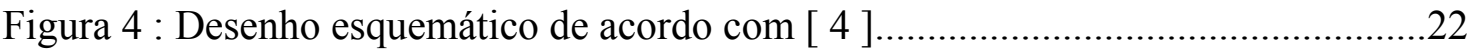

Figura 5 : Posição dos termopares nos tubos...................................................................24

Figura 6 : Esquema de medição dos termopares........................................................25

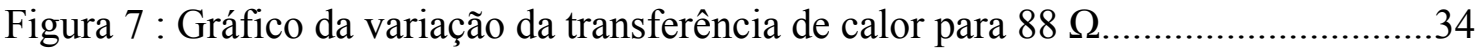

Figura 8 : Gráfico da variação da transferência de calor para $50 \Omega$ (.............................34

Figura 9 : Gráfico da variação da transferência de calor para $50 \Omega$ e $80 \Omega$ ligados em

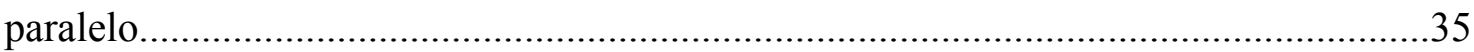

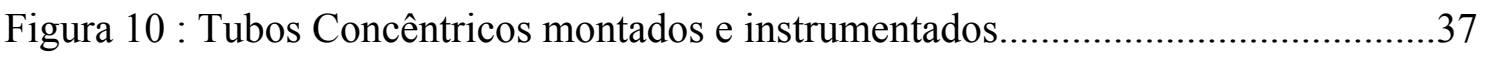

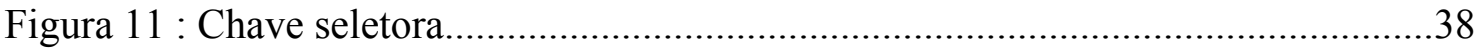

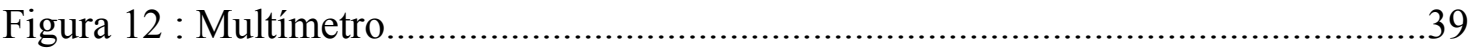

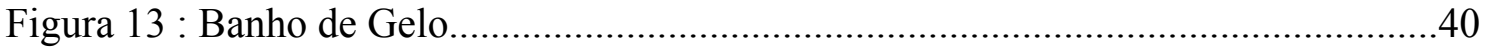

Figura 14 : Resistência responsável pela geração de calor............................................41

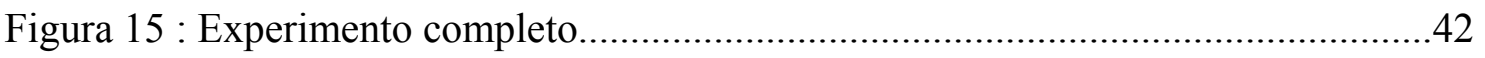




\section{Índice de Equações}

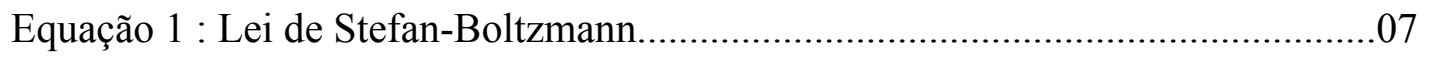

Equação 2 : A emissividade espectral hemisférica..................................................08

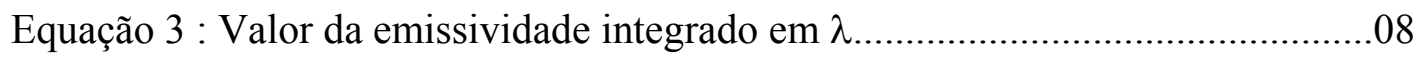

Equação 4 : Calor trocado entre as superfícies no espaço anular...............................22

Equação 5 : Variação da voltagem de acordo com o material...................................24

Equação 6 : Curva que relaciona temperatura e voltagem......................................25

Equação 7 : Incerteza associada ao experimento...................................................28

Equação 8 : Resoluções dos equipamentos utilizados............................................29

Equação 9 : O valor da emissividade encontrado utilizando o termovisor.................30

Equação 10 : Potência associada a radiação.............................................................30

Equação 11 : Expressão das incertezas associadas às áreas.....................................31

Equação 12 : O valor da incerteza associada à potência da radiação........................31

Equação 13 : Incerteza associada à potência gerada pela resistência........................32

Equação 14 : O valor da incerteza associada à potência da resistência......................32

Equação 15 : Incerteza associada à potência de convecção.....................................33

Equação 16 : O valor da incerteza associada à potência da convecção......................33 


\section{Índice de Tabelas}

Tabela 1: Emissividade de materiais não metálicos para várias temperaturas

Tabela 2: Emissividade de materiais metálicos para várias temperaturas.

Tabela 3 : Medidas obtidas nos termopares e a temperatura ambiente no momento para

o caso da resistência de $88 \Omega$. 30

Tabela 4 - As medidas dos termopares convertidas para temperaturas, as médias e o desvio padrão associado para o caso da resistência de $88 \Omega$

Tabela 5 - Cálculo das Potências e o valor do coeficiente de transferência para o caso da resistência de $88 \Omega$.

Tabela 6 - Medidas obtidas nos termopares e a temperatura ambiente no momento para o caso da resistência de $50 \Omega$

Tabela 7 - As medidas dos termopares convertidas para temperaturas, as médias e o desvio padrão associado para o caso da resistência de $50 \Omega$

Tabela 8 - Cálculo das Potências e o valor do coeficiente de transferência para o caso da resistência de $50 \Omega$.

Tabela 9 - Medidas obtidas nos termopares e a temperatura ambiente no momento para o caso das resistências de $50 \Omega$ e de $80 \Omega$ ligadas em paralelo.

Tabela 10 - As medidas dos termopares convertidas para temperaturas, as médias e o desvio padrão associado para o caso das resistências de $50 \Omega$ e de $80 \Omega$ ligadas em paralelo

Tabela 11 - Cálculo das Potências e o valor do coeficiente de transferência para o caso das resistências de $50 \Omega$ e de $80 \Omega$ ligadas em paralelo .32 


\section{INTRODUÇÃO}

O monitoramento da temperatura de equipamentos e sistemas de usinas hidrelétricas e subestações é uma ferramenta utilizada para o planejamento da sua manutenção, quer seja preditiva ou corretiva. Quando a temperatura se eleva a valores superiores aos especificados pelo fabricante dos equipamentos, ou projetista dos sistemas, considera-se que deve ter havido uma deteriorização do desempenho, e, portanto, procedimentos de manutenção devem ser aplicados para restauração das suas características originais Quanto mais rápido for o reconhecimento desta anormalidade, menores serão os prejuízos provocados pela interrupção do funcionamento e menores serão os custos de manutenção.

Desta forma, o monitoramento continuo é uma ferramenta importante de acompanhamento do desempenho. Ele pode ser feito com a instalação de sensores tradicionais, como termopares e termo-resistências, o que requer muitas vezes a parada das máquinas para sua colocação, com os prejuízos associados. Ultimamente, entretanto, a tecnologia de medição remota de temperatura tem se desenvolvido de modo a se tornar importante para o diagnóstico de mal funcionamento.

A termografia analisa a radiação infravermelha emitida pelo alvo, objeto da análise, e interpreta o sinal, associando uma temperatura ao mesmo, pelas leis da transferência de calor por radiação. Os equipamentos existentes, chamados de termovisores, indicam com uma razoável exatidão o valor de temperatura quando as condições de observação são ideais, isto é, uniformidade de temperatura, e conhecimento das propriedades radiantes da superfície emissora. Quando este não é o 
caso, isto é, quando a superfície não é uniforme em temperatura, e quando as propriedades superficiais do alvo não são conhecidas, um problema de interpretação do sinal surge, fazendo com que esta ferramenta se torne mais qualitativa do que quantitativa. Muitas vezes, por exemplo, existe entre o alvo e o termovisor uma janela de observação, e sua transparência deve ser levada em consideração.

Assim, o uso adequado do termovisor para indicar com exatidão a temperatura depende de uma calibração do mesmo, e da interpretação do sinal do mesmo em diferentes condições de operação, normalmente diferentes das de calibração.

Pretende-se neste projeto formar uma infraestrutura calibrar seus termovisores e interpretar adequadamente o sinal infravermelho. Para isto, será desenvolvida uma metodologia para analisar os resultados, consistindo da sua calibração em condições ideais, determinação das propriedades superficiais de radiação (usando também o próprio termovisor e equipamentos auxiliares), e procedimentos para a separação dos diferentes sinais, calculando a influência de cada um sobre a incerteza da temperatura desejada, o que será objeto principal desta análise. As necessidades de sensoriamento da temperatura, que o projeto procurará atender são :

[1] Temperatura dos rotores dos geradores

[2] Temperatura dos enrolamentos estatóricos

[3] Temperatura das juntas de vedação dos eixos

[4] Temperatura de resfriadores de ar

[5] Temperatura de óleo e enrolamento de transformadores $\quad: 0{ }^{\circ} \mathrm{C}$ a $150{ }^{\circ} \mathrm{C}$

[6] Temperatura de contatos elétricos
: $0{ }^{\circ} \mathrm{C}$ a $150{ }^{\circ} \mathrm{C}$

: $0{ }^{\circ} \mathrm{C}$ a $120{ }^{\circ} \mathrm{C}$

: $0{ }^{\circ} \mathrm{C}$ a $150{ }^{\circ} \mathrm{C}$

: $0{ }^{\circ} \mathrm{C}$ a $110{ }^{\circ} \mathrm{C}$

: até $350^{\circ} \mathrm{C}$ 
As tolerâncias desejadas parta os itens 1 a 5 são de 2\%. Já para o item 6 aumenta para $5 \%$

A indicação de temperatura pelo termovisor, segundo o fabricante, tem uma incerteza de $\pm 2{ }^{\circ} \mathrm{C}$, ou $2 \%$, o que for maior. O termovisor tem o ajuste da emissividade, que deve ser conhecida para que se consiga sua calibração.

A emissividade da superfície será estimada através de duas metodologias.

- $1^{a}$ metodologia : Inicialmente, o termovisor será calibrado contra um corpo negro existente no INMETRO na faixa da temperatura ambiente até $150{ }^{\circ} \mathrm{C}$. Após esta fase, o termovisor será utilizado para medição da temperatura da superfície de uma placa, pintada de preto e colocada em um banho de temperatura controlada. Sua temperatura será medida com termopares calibrados contra padrões rastreados à Rede Brasileira de Calibração. Variandose a emissividade ajustada no termovisor até que a temperatura medida coincida com a temperatura indicada pelo termovisor, pode-se estimar a emissividade da superfície.

- 2a metodologia : Através de um balanço térmico em um sistema que consiste de dois cilindros concêntricos, com as superfícies do espaço anular pintadas de preto, e um resistência elétrica inserida no cilindro interno para o fornecimento de calor ao sistema. Este pode ser considerado radial, pois as bases estão isoladas.

O LAPIR (INMETRO) utiliza um corpo negro para a calibração. Desta forma, a emissividade do material da cavidade não é importante, e, a radiação emitida pela mesma tem a característica daquela de um corpo negro. A temperatura do corpo negro 
pode então ser comparada com a indicada pelo termovisor, ajustado para uma emissividade igual a 1 , na faixa de interesse de $25{ }^{\circ} \mathrm{C}$ até $150{ }^{\circ} \mathrm{C}$.

O presente trabalho trata do desenvolvimento de um dispositivo para a medição da emissividade pela $2^{\underline{a}}$ metodologia. O ponto de partida é o trabalho desenvolvido em [1]. A contribuição deste trabalho é o estabelecimento de vácuo no espaço anular. Desta forma, a incerteza de medição será menor. Esta será estimada seguindo a metodologia descrita em [1]. Os resultados serão comparados com os já obtidos pela $1^{\mathrm{a}}$ metodologia . 


\section{FUNDAMENTOS TEÓRICOS}

\subsection{Fundamentos da transferência de calor}

Os fenômenos da transferência de calor desempenham um papel importante em muitos problemas industriais e de meio ambiente. Nos casos de transferência de calor são estudados três processos de transferência:

- Condução : Difusão de energia devido ao movimento molecular aleatório.

- Convecção : Difusão de energia devido ao movimento aleatório molecular e ao transporte de energia devido ao movimento global do fluido.

- Radiação : Energia transferida por ondas eletromagnéticas e/ou fótons.

Neste trabalho iremos estudar a calibração de emissividade considerando o efeito da radiação e da convecção e para isso iremos ter um meio gerador de energia de maneira que não haja contato, apenas transporte. Este mecanismo será descrito em breve no tópico 3 Procedimento Experimental.

Radiação é emissão de energia pela matéria e seu transporte não exige a presença de qualquer meio material. Com relação à natureza deste transporte, podemos tratar a radiação como uma onda, propagação de ondas eletromagnéticas e, ao mesmo tempo, propagação de matéria, as partículas denominadas de fótons. De qualquer modo, 
radiação térmica é a energia emitida por um corpo pelo fato de sua temperatura estar acima do zero absoluto e a ela podem ser atribuídas as propriedades típicas de uma onda, ou seja, a freqüência $v$ e o comprimento de onda $\lambda$.

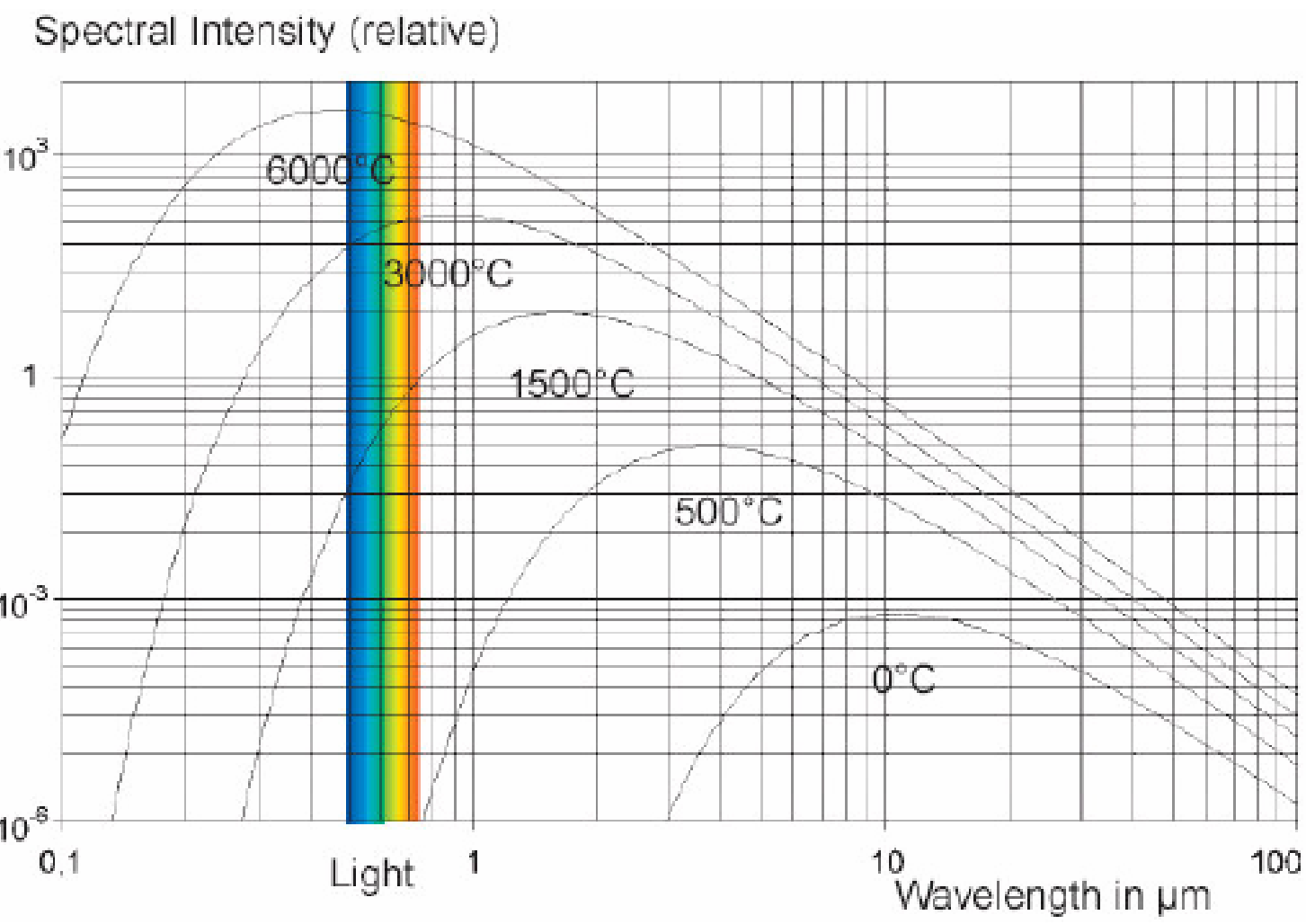

Figura 1 - Emitância espectral de corpo negro para 5 temperaturas, $\log x \log$.

A radiação térmica se distingue de outros tipos de radiação, como ondas de rádio e raios-x, pelo fato destas não se propagarem como conseqüência da temperatura do corpo. A banda de comprimento de ondas, conhecido como espectro ou freqüências, da radiação térmica vai de $0,1 \mu \mathrm{m}$ a $100 \mu \mathrm{m}\left(3 \times 10^{15} \mathrm{~Hz}\right.$ e $3 \times 10^{12} \mathrm{~Hz}$, respectivamente).

O radiador térmico ideal é chamado de corpo negro. Este corpo absorve toda a radiação nele incidente e, para uma dada temperatura, emite o máximo possível de radiação térmica.

A radiação térmica total emitida pelo corpo negro é dada por (Lei de Stefan-Boltzmann) 


$$
\mathrm{E}_{\mathrm{b}}=\sigma \mathrm{T}^{4}
$$

onde

$$
\begin{aligned}
& \mathrm{E}_{\mathrm{b}} \equiv \text { emitância total }\left[\mathrm{W} / \mathrm{m}^{2}\right] \\
& \sigma=5,6697 \times 10^{-8}\left[\mathrm{~W} / \mathrm{m}^{2} \cdot \mathrm{K}^{4}\right] \equiv \text { constante de Stefan-Boltzmann } \\
& \mathrm{T} \equiv \text { temperatura absoluta }[\mathrm{K}]
\end{aligned}
$$

Embora o corpo negro seja uma idealização física e matemática, é possível construir radiadores reais cujo comportamento se aproxima muito do comportamento do corpo negro.

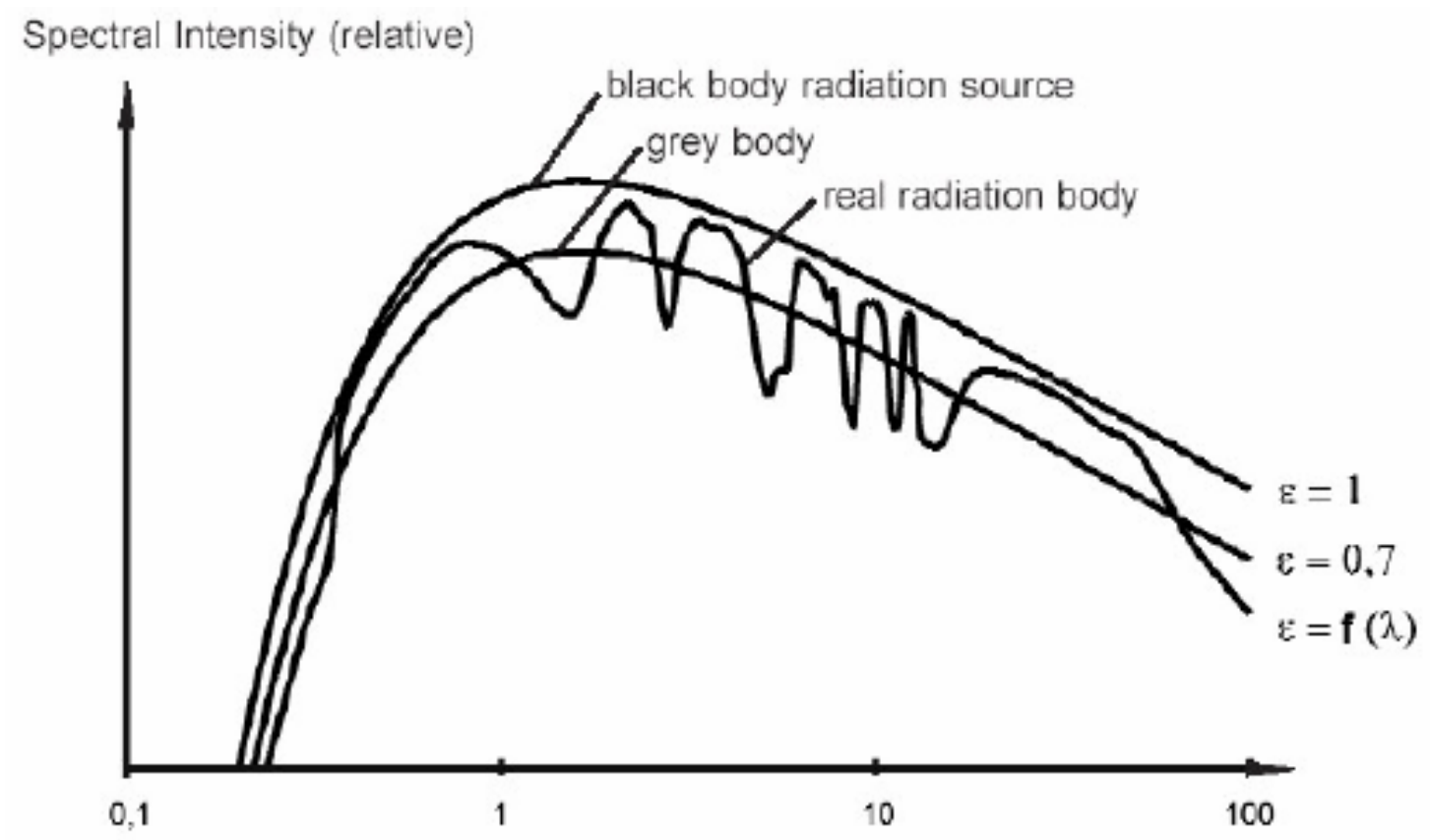

Figura 2 - Emissividade em corpos negros, cinzentos e reais (qualitativo).

Estas fontes de radiação são necessárias para a calibração de medidores de temperatura por radiação. Por outro lado, os corpos cuja temperatura deseja-se medir no dia-a-dia podem desviar-se substancialmente do comportamento do corpo negro. A razão entre as emitâncias real e de corpo negro é o que se denomina de emissividade do corpo real. Vários tipos de emissividade foram definidos, em função de interesses 
específicos. A emissividade pode ser espectral hemisférica, total, hemisférica seletiva, etc. A definição mais básica é a da emissividade espectral hemisférica, E $\lambda, \mathrm{T}$, de um corpo real à temperatura $\mathrm{T}$. Admitamos que ela possa ser medida utilizando filtros, de modo a que somente a emitância em um comprimento de onda se propague. São os chamados filtros ópticos seletivos. A emissividade espectral hemisférica é dada por :

$$
\varepsilon_{\lambda, \mathrm{T}}=\frac{\mathrm{E}_{\lambda}}{\mathrm{E}_{\lambda, \mathrm{b}}}
$$

onde E $\lambda$, b é a emitância espectral do corpo negro à mesma temperatura, isto é, mesmos comprimentos de onda e temperatura. Portanto, a emissividade é uma quantidade adimensional, sempre menor do que 1,0 para corpos reais. Note também que, no caso mais geral, é função de $\lambda$ e $\mathrm{T}$ (eventualmente, numa pequena faixa limitada de $\lambda$ e $\mathrm{T}$, pode ter valor semelhante e constante, mas não é o caso geral).Como no escopo do projeto não incluiu o trabalho em função do comprimento de onda, iremos usar o valor da emissividade integrado em $\lambda$. Desta maneira temos o valor que será trabalhado experimentalmente através da seguinte equação:

$\int_{0}^{\infty} E_{\lambda} \partial \lambda=\int_{0}^{\infty} \varepsilon_{\lambda, T} . E_{\lambda, b} \partial \lambda=\varepsilon \cdot E_{b}=\varepsilon \cdot \sigma T^{4} \quad$ onde $E_{\lambda}=\varepsilon_{\lambda, T} . E_{\lambda, b}$

Estes valores foram extraídos de Sierra Pacific Corporation (SPI Infrared) 
Tabela 1 : Emissividade de materiais não metálicos para várias faixas de temperatura

\begin{tabular}{|c|c|c|c|}
\hline Material & Temperature (F) & (C) & E-Emissivity \\
\hline Adobe & 68 & 20 & .90 \\
\hline Board & 100 & 38 & .96 \\
\hline Cement & $32-392$ & $0-200$ & .96 \\
\hline Cement, Red & 2500 & 1371 & .67 \\
\hline Cement, White & 2500 & 1317 & .65 \\
\hline Cloth & 199 & 93 & .90 \\
\hline Paper & $100-700$ & $38-371$ & .93 \\
\hline Slate & 68 & 20 & .72 \\
\hline Asphalt, pavement & 100 & 38 & .93 \\
\hline Asphalt, tar paper & 68 & 20 & .93 \\
\hline Basalt & 68 & 20 & .72 \\
\hline Red, rough & 70 & 21 & .93 \\
\hline Gault Cream & $2500-5000$ & $1371-2760$ & $.26-.30$ \\
\hline Fire Clay & 2500 & 1371 & .75 \\
\hline Lime Clay & 2500 & 1371 & .43 \\
\hline Fire Brick & 1832 & 100 & $.75-.80$ \\
\hline Magnesite, Refractory & 1832 & 1000 & .38 \\
\hline Gray Brick & 2021 & 1100 & .75 \\
\hline Silica, Glazed & 2000 & 1093 & .88 \\
\hline Silica, Unglazed & 2000 & 1093 & .80 \\
\hline Sandlime & $2500-5000$ & $1371-2760$ & $.59-.63$ \\
\hline Carborundum & 1850 & 1010 & .92 \\
\hline Alumina on Inconel & $800-2000$ & $427-1093$ & $.69-.45$ \\
\hline Earthenware, Glazed & 70 & 21 & .90 \\
\hline Earthenware, Matte & 70 & 21 & .93 \\
\hline Greens No. 5210-2C & $200-750$ & 93-399 & $.89-.82$ \\
\hline Coating No. C20A & $200-750$ & 93-399 & $.73-.80$ \\
\hline Porcelain & 72 & 22 & .92 \\
\hline White Al2O3 & 200 & 93 & .90 \\
\hline Zirconia on Inconel & $800-2000$ & $427-1093$ & $.62-.45$ \\
\hline
\end{tabular}




\begin{tabular}{|c|c|c|c|}
\hline Material & Temperature (F) & (C) & E-Emissivity \\
\hline Clay & 68 & 20 & .39 \\
\hline " Fired & 158 & 70 & .91 \\
\hline " Shale & 68 & 20 & .69 \\
\hline " Tiles, Light Red & $2500-5000$ & $1371-2760$ & $.32-.34$ \\
\hline " Tiles, Dark Purple & $2500-5000$ & $1371-2760$ & .78 \\
\hline \multicolumn{4}{|l|}{ Concrete } \\
\hline Rough & $32-2000$ & $0-1093$ & .94 \\
\hline Tiles, Natural & $2500-5000$ & $1371-2760$ & $.63-.62$ \\
\hline "Brown & $2500-5000$ & $1371-2760$ & $.87-.83$ \\
\hline " Black & $2500-5000$ & $1371-2760$ & $.94-.91$ \\
\hline Cotton Cloth & 68 & 20 & .77 \\
\hline Dolomite Lime & 68 & 20 & .41 \\
\hline Emery Corundum & 176 & 80 & .86 \\
\hline Convex D & 212 & 100 & .80 \\
\hline Convex D & 600 & 316 & .82 \\
\hline Convex D & 932 & 500 & .76 \\
\hline Nonex & 212 & 100 & .82 \\
\hline Nonex & 939 & 500 & .76 \\
\hline Smooth & $32-200$ & $0-93$ & $.92-.94$ \\
\hline Granite & 70 & 21 & .45 \\
\hline Gravel & 100 & 38 & .28 \\
\hline Gypsum & 68 & 20 & $.80-.90$ \\
\hline Ice, Smooth & 32 & 0 & .97 \\
\hline Ice, Rough & 32 & 0 & .98 \\
\hline Black & 200 & 93 & .96 \\
\hline Blue, on Al Foil & 100 & 38 & .78 \\
\hline Clear, on Al Foil (2 coats) & 200 & 93 & $.08(.09)$ \\
\hline Clear, on Bright $\mathrm{Cu}$ & 200 & 93 & .66 \\
\hline Clear, on Tarnished $\mathrm{Cu}$ & 200 & 93 & .64 \\
\hline Red, on Al Foil (2 coats) & 200 & 93 & $.61(.74)$ \\
\hline White & 200 & 93. & .95 \\
\hline White, on Al Foil (2 coats) & 100 & 38 & $.69(.88)$ \\
\hline
\end{tabular}




\begin{tabular}{|c|c|c|c|}
\hline Material & Temperature (F) & (C) & E-Emissivity \\
\hline Yellow, on Al Foil (2 coats) & 100 & 38 & $.57(.79)$ \\
\hline Lime Mortar & $100-500$ & $38-260$ & $.90-.92$ \\
\hline Limestone & 100 & 38 & .95 \\
\hline Marble, White & 100 & 38 & .95 \\
\hline " Smooth, White & 100 & 38 & .56 \\
\hline " Polished Gray & 100 & 38 & .75 \\
\hline Mica & 100 & 38 & .75 \\
\hline 0.001 Film & 72 & 22 & .27 \\
\hline $0.002 "$ & 72 & 22 & .46 \\
\hline $0.005 "$ & 72 & 22 & .72 \\
\hline Thick " & 72 & 22 & .82 \\
\hline \multicolumn{4}{|l|}{ Oil, Linseed } \\
\hline On Al Foil, uncoated & 250 & 121 & .09 \\
\hline On Al Foil, 1 coat & 250 & 121 & .56 \\
\hline On Al Foil, 2 coats & 250 & 121 & .56 \\
\hline On Polished Iron, .001 Film & 100 & 38 & .22 \\
\hline On Polished Iron, .002 Film & 100 & 38 & .45 \\
\hline On Polished Iron, .004 Film & 100 & 38 & .65 \\
\hline On Polished Iron, Thick Film & 100 & 38 & .83 \\
\hline Blue, Cu2O3 & 75 & 24 & .94 \\
\hline Black, CuO & 75 & 24 & .96 \\
\hline Green, Cu2O3 & 75 & 24 & .92 \\
\hline Red, Fe2O3 & 75 & 24 & .91 \\
\hline White, Al2O3 & 75 & 24 & .94 \\
\hline White, Y2O3 & 75 & 24 & .90 \\
\hline White, $\mathrm{ZnO}$ & 75 & 24 & .95 \\
\hline White, $\mathrm{MgCO} 3$ & 75 & 24 & .91 \\
\hline White, $\mathrm{ZrO} 2$ & 75 & 24 & .95 \\
\hline White, ThO2 & 75 & 24 & .90 \\
\hline White, MgO & 75 & 24 & .91 \\
\hline White, $\mathrm{PbCO} 3$ & 75 & 24 & .93 \\
\hline Yellow, PbO & 75 & 24 & .90 \\
\hline
\end{tabular}




\begin{tabular}{|c|c|c|c|}
\hline Material & Temperature (F) & (C) & E-Emissivity \\
\hline Yellow, PbCrO4 & 75 & 24 & .93 \\
\hline Paints, Aluminium & 100 & 38 & $.27-.67$ \\
\hline $10 \% \mathrm{Al}$ & 100 & 38 & .52 \\
\hline $26 \% \mathrm{Al}$ & 100 & 38 & .30 \\
\hline Dow XP-310 & 200 & 93 & .22 \\
\hline Paints, Bronze & low & low & $.34-.80$ \\
\hline Gum Varnish (2 coats) & 70 & 21 & .53 \\
\hline Gum Varnish ( 3 coats) & 70 & 21 & .50 \\
\hline Cellulose Binder (2 coats) & 70 & 21 & .34 \\
\hline All colors & 200 & 93 & $.92-.96$ \\
\hline Black & 200 & 93 & .92 \\
\hline Black Gloss & 70 & 21 & .90 \\
\hline Camouflage Green & 125 & 52 & .85 \\
\hline Flat Black & 80 & 27 & .88 \\
\hline Flat White & 80 & 27 & .91 \\
\hline Gray-Green & 70 & 21 & .95 \\
\hline Green & 200 & 93 & .95 \\
\hline Lamp Black & 209 & 98 & .96 \\
\hline Red & 200 & 93 & .95 \\
\hline White & 200 & 93 & .94 \\
\hline Quartz, Rough, Fused & 70 & 21 & .93 \\
\hline Glass, $1.98 \mathrm{~mm}$ & 540 & 282 & .90 \\
\hline Glass, $1.98 \mathrm{~mm}$ & 1540 & 838 & .41 \\
\hline Glass, $6.88 \mathrm{~mm}$ & 540 & 282 & .93 \\
\hline Glass, $6.88 \mathrm{~mm}$ & 1540 & 838 & .47 \\
\hline Opaque & 570 & 299 & .92 \\
\hline Opaque & 1540 & 838 & .68 \\
\hline Red Lead & 212 & 100 & .93 \\
\hline Rubber, Hard & 74 & 23 & .94 \\
\hline Rubber, Soft, Gray & 76 & 24 & .86 \\
\hline Sand & 68 & 20 & .76 \\
\hline Sandstone & 100 & 38 & .67 \\
\hline Sandstone, Red & 100 & 38 & $.60-.83$ \\
\hline
\end{tabular}




\begin{tabular}{|c|c|c|c|}
\hline Material & Temperature (F) & (C) & E-Emissivity \\
\hline Sawdust & 68 & 20 & .75 \\
\hline Shale & 68 & 20 & .69 \\
\hline Silica,Glazed & 1832 & 1000 & .85 \\
\hline Silica, Unglazed & 2012 & 1100 & .75 \\
\hline Silicon Carbide & $300-1200$ & $149-649$ & $.83-.96$ \\
\hline Silk Cloth & 68 & 20 & .78 \\
\hline Slate & 100 & 38 & $.67-.80$ \\
\hline Snow, Fine Particles & 20 & $\mid-7$ & .82 \\
\hline Snow, Granular & 18 & -8 & .89 \\
\hline Surface & 100 & 38 & .38 \\
\hline Black Loam & 68 & 20 & .66 \\
\hline Plowed Field & 68 & 20 & .38 \\
\hline Acetylene & 75 & 24 & .97 \\
\hline Camphor & 75 & 24 & .94 \\
\hline Candle & 250 & 121 & .95 \\
\hline Coal & 68 & 20 & .95 \\
\hline Stonework & 100 & 38 & .67 \\
\hline Water & 100 & 38 & .67 \\
\hline Waterglass & 68 & 20 & .96 \\
\hline Wood & low & low & $.80-.90$ \\
\hline Beech Planed & 158 & 70 & .94 \\
\hline Oak, Planed & 100 & 38 & .91 \\
\hline
\end{tabular}


Tabela 2 : Emissividade de materiais metálicos para várias faixas de temperatura

Material Temp. $\left({ }^{\circ} \mathrm{C}\right)$ Normal emissivity, $\mathbf{E}_{\mathbf{n}}$

Aluminum

$\begin{array}{lll}\text { Unoxidized } & 100 & 0.03\end{array}$

Unoxidized $\quad 500 \quad 0.06$

$\begin{array}{lll}\text { Oxidized } & 200 & 0.11\end{array}$

$\begin{array}{lll}\text { Oxidized } & 600 & 0.19\end{array}$

Monel, Ni-Cu

Unoxidized $\quad 200 \quad 0.41$

Unoxidized $\quad 600 \quad 0.46$

$\begin{array}{lll}\text { Polished } & 40 & 0.05\end{array}$

$\begin{array}{lll}\text { Oxidized } & 40 & 0.31\end{array}$

$\begin{array}{lll}\text { Oxidized } & 250 & 0.46\end{array}$

Steel

$\begin{array}{lll}\text { Unoxidized } & 100 & 0.08\end{array}$

$\begin{array}{lll}\text { Oxidized } & 100 & 0.80\end{array}$

Stainless Steel

$\begin{array}{lll}\text { Polished } & 100 & 0.22\end{array}$

$\begin{array}{lll}\text { Polished } & 425 & 0.45\end{array}$ 


\subsection{Calibração de termômetros infravermelhos no Brasil}

Apesar de haver uma grande demanda de serviços de calibração de sensores de temperatura por radiação, no Brasil, há somente dois laboratórios credenciados à Rede Brasileira de Calibração - RBC e o próprio INMETRO, capazes de realizar com competência técnica e rastreabilidade aos padrões nacionais de mais alta exatidão, garantindo assim, a base técnica imprescindível ao livre comércio nos mercados globalizados e a disseminação do conhecimento técnico na área medição de temperatura sem contato.

Os laboratórios de calibração de sensores de temperatura por radiação no Brasil são:

- INMETRO : O Laboratório de Pirometria - LAPIR oferece serviços de calibração na faixa de medição $25^{\circ} \mathrm{C}$ a $1500^{\circ} \mathrm{C}$ com incerteza de medição variando entre $\pm 2^{\circ} \mathrm{C} \mathrm{a} \pm 4^{\circ} \mathrm{C}$, para termômetros de radiação infravermelha, e de $800^{\circ} \mathrm{C}$ a $2200^{\circ} \mathrm{C}$ com incerteza de medição variando entre $\pm 2,5^{\circ} \mathrm{C}$ a $\pm 5^{\circ} \mathrm{C}$ para sensores de radiação que operam dentro do espectro visível.

- USIMINAS : O Laboratório de Calibração de Instrumentação - IHI oferece serviços de calibração de termômetros de radiação infravermelha nas seguintes faixas de medição: de $50^{\circ} \mathrm{C}$ até $<550^{\circ} \mathrm{C}$ com menor incerteza de medição de $\pm 1,0^{\circ} \mathrm{C}$, de $550^{\circ} \mathrm{C}$ até $<1100^{\circ} \mathrm{C}$ com menor incerteza de medição de $\pm 1,6^{\circ} \mathrm{C}$ e de $1100^{\circ} \mathrm{C}$ até $1500^{\circ} \mathrm{C}$ com menor incerteza de medição de $\pm 1,4^{\circ} \mathrm{C}$ até $\pm 2,1^{\circ} \mathrm{C}$.

- CST : O Laboratório de Calibração oferece serviços de calibração de termômetros de radiação infravermelha nas seguintes faixas de medição: de 
$500^{\circ} \mathrm{C}$ até $1100^{\circ} \mathrm{C}$ com menor incerteza de medição de $\pm 1,7^{\circ} \mathrm{C}$ e de $1100^{\circ} \mathrm{C}$ até $1500^{\circ} \mathrm{C}$ com menor incerteza de medição de $\pm 3,5^{\circ} \mathrm{C}$.

O Laboratório de Pirometria ( LAPIR ) possui a melhor infraestrutura no Brasil para realizar a calibração de sensores de temperatura por radiação infravermelha que operam acima de $25^{\circ} \mathrm{C}$.

Os principais equipamentos para realizar a calibração são:

- Cavidade de corpo negro de média temperatura. A faixa de operação deste equipamento é de $25^{\circ} \mathrm{C}$ a $1150^{\circ} \mathrm{C}$, tendo como padrão de temperatura um termopar tipo $\mathrm{S}$ calibrado por pontos fixos no Laboratório de Temperatura ( LATER ) do INMETRO, com uma incerteza de medição de $0,3^{\circ} \mathrm{C}$. Sua cavidade de corpo negro possui um diâmetro de $50 \mathrm{~mm}$ e uma profundidade de $430 \mathrm{~mm}$, o que possibilita que seja alcançado um valor de emissividade de 0,998 .

- Cavidade de corpo negro de alta temperatura. A faixa de operação deste equipamento é de $1000^{\circ} \mathrm{C}$ a $1500^{\circ} \mathrm{C}$, tendo como padrão de referência um termopar tipo B ou um termômetro de radiação. Caso uma maior exatidão seja necessária, o termômetro de radiação deve ser utilizado, uma vez que não existem pontos fixos intermediários entre o ponto de solidificação de cobre, $1084,62^{\circ} \mathrm{C}$ [4] e o ponto de solidificação do paládio, $1553^{\circ} \mathrm{C}$. Sua cavidade de corpo negro possui um diâmetro de $40 \mathrm{~mm}$ e uma profundidade de $430 \mathrm{~mm}$, o que possibilita que seja alcançado um valor de emissividade de 0,998.

- Pirômetro Padrão Primário. A faixa de operação deste equipamento é de $680^{\circ} \mathrm{C}$ até $3500^{\circ} \mathrm{C}$, é o instrumento de mais alta qualidade metrológica disponível no 
Laboratório de Pirometria ( LAPIR ), possui um sistema óptico .que requer um tamanho mínimo de alvo 0,6 mm, a uma distância de $400 \mathrm{~mm}$.

- Multímetro. Como instrumento de leitura dos sensores de temperatura por contato, como o termopar tipo $\mathrm{S}$ da cavidade de corpo negro de média temperatura, é utilizado um multímetro de $7 \quad \frac{1}{2} 2$ dígitos, calibrado nos laboratórios da Divisão de Metrologia Elétrica do INMETRO. Este equipamento possui interface IEE488, possibilitando que as leituras sejam realizadas de modo automático, controladas pelo computador.

Pela faixa de medição do objeto e para poder minimizar a incerteza de medição durante a calibração em elevadas temperaturas, esta é dividida em duas etapas; a primeira foi realizada na cavidade de corpo negro de média temperatura e a segunda, na cavidade de corpo negro de alta temperatura.

A primeira etapa de calibração é realizada na faixa de temperatura de $800^{\circ} \mathrm{C}$ a $1050^{\circ} \mathrm{C}$, em intervalos de $50^{\circ} \mathrm{C}$ em $50^{\circ} \mathrm{C}$ utilizando como padrão de referência da cavidade de corpo negro, um termopar tipo S. Primeiro, fixa-se o objeto em uma base que desliza sobre um trilho que possui uma escala milimetrada fixa o que permite posicioná-lo à distância de $\pm 1 \mathrm{~m}$ do fundo da cavidade de corpo negro. Esta base faz com que o eixo de simetria do objeto fique paralelo e coincidente ao eixo de simetria da cavidade de corpo negro, Fig. 3.

Antes de iniciar a calibração, o objeto permanece ligado à energia elétrica por no mínimo 15 minutos, para então iniciar a calibração. 
Todos os pontos de calibração da primeira etapa foram realizados da seguinte forma. Primeiro, ajusta-se o controlador do forno da cavidade de corpo negro para a temperatura nominal de calibração, por exemplo, $800^{\circ} \mathrm{C}$; assim que o forno indica que tinha atingido a temperatura nominal de trabalho, faz-se a leitura da tensão que o padrão de referência fornece através de Multímetro. Esta leitura é feita de forma automática com o auxílio de um microcomputador com placa A/D e um software específico para aquisição de dados.

A calibração somente é realizada quando a diferença de temperatura indicada pelo padrão de referência não é maior que $0,1^{\circ} \mathrm{C}$ em um intervalo de tempo de $5 \mathrm{~min}$, garantindo que a cavidade de corpo negro esta à mesma temperatura. $\mathrm{C}$, com intervalos de 10 s entre cada leitura.

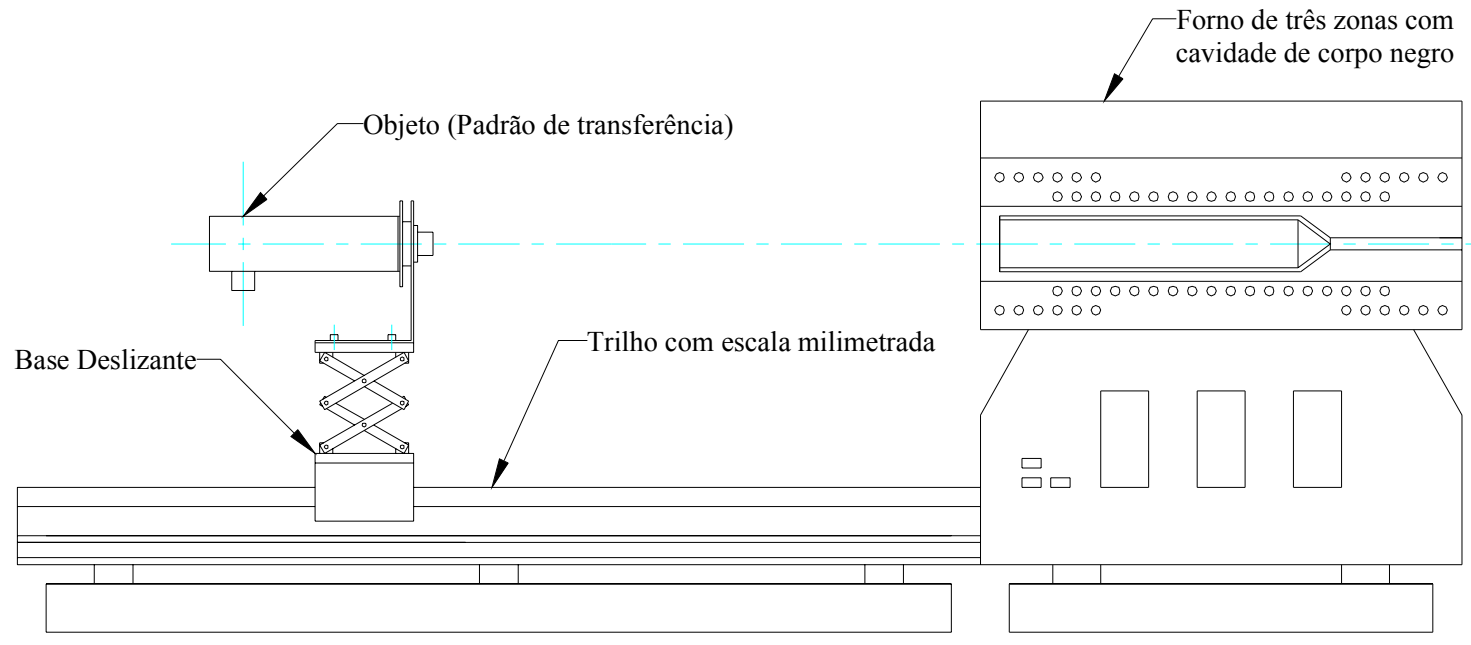

Figura 3 - Desenho esquemático da calibração de pirômetro infravermelho realizada no

\section{LAPIR (INMETRO).}

A segunda etapa de calibração é realizada na faixa de temperatura de $1100^{\circ} \mathrm{C}$ a $1500^{\circ} \mathrm{C}$, em intervalos de $50^{\circ} \mathrm{C}$ em $50^{\circ} \mathrm{C}$ utilizando como padrão de referência da cavidade de corpo negro, um pirômetro infravermelho. 
Da mesma forma que na primeira etapa de calibração, o objeto é fixado na base, posicionado a uma distância de $\pm 1 \mathrm{~m}$ do fundo da cavidade de corpo negro e alinhado ao seu eixo de simetria, como na Fig. 3.

Todos os pontos de calibração da segunda etapa são realizados, primeiro ajustando-se o controlador do forno da cavidade de corpo negro para a temperatura nominal de calibração, por exemplo, $1100^{\circ} \mathrm{C}$. Assim que o forno indica que tinha atingido a temperatura nominal de trabalho, faz-se a leitura da temperatura da cavidade de corpo negro com o objeto. A calibração somente é realizada quando a diferença de temperatura indicada pelo objeto não é maior que $1^{\circ} \mathrm{C}$ em um intervalo de tempo de 10 min, garantindo que a cavidade de corpo negro está à mesma temperatura. Com esta condição satisfeita realizam-se dez leituras de temperatura com o objeto em intervalos de 10s entre cada leitura. Logo a seguir retira-se o objeto e coloca-se o padrão de referência à mesma distância e alinhamento do objeto, para, então, efetuar 10 leituras de temperatura em intervalos de 10 s entre cada.

Como principais fontes de incerteza na calibração, pode-se citar em ordem decrescente de grandeza as seguintes.

- Estabilidade da temperatura da cavidade de corpo negro. Apesar da boa estabilidade da temperatura da cavidade de corpo negro de média temperatura ( $800^{\circ} \mathrm{C}$ a $1050^{\circ} \mathrm{C}$ ) não variar $0,1^{\circ} \mathrm{C}$ em 5 min. A parcela da contribuição de incerteza de medição devido à estabilidade de temperatura na cavidade de corpo negro é considerada igual a $\pm 1{ }^{\circ} \mathrm{C}$ com distribuição de probabilidade retangular, 
devido a não homogeneidade de temperatura no interior da cavidade de corpo negro de alta temperatura.

- Distância focal do objeto. A contribuição desta parcela de incerteza é determinada posicionando-se o objeto a diferentes distâncias do fundo da cavidade de corpo negro, mantendo-o alinhado com o eixo de simetria da cavidade de corpo negro, conforme figura 3. Então, verifica-se o quanto a indicação de temperatura feita pelo objeto varia. Devido à excelente qualidade do objeto, pois sua distância de foco obedece à razão 1:82, a parcela de incerteza de medição devido à distância focal é considerada igual a $\pm 1^{\circ} \mathrm{C}$, com distribuição de probabilidade retangular.

- Padrão de referência da cavidade de corpo negro de alta temperatura. Parcela de incerteza de medição retirada do certificado de calibração.

- Resolução do objeto. Parcela de incerteza de medição considerada igual a $\pm 1{ }^{\circ} \mathrm{C}$ com distribuição de probabilidade retangular.

- Multímetro utilizado nas medições de tensão do padrão de referência da cavidade de corpo negro de média temperatura.Esta parcela de incerteza de medição é estimada como sendo de $\pm 0,1^{\circ} \mathrm{C}$ com distribuição de probabilidade normal,.

Para temperaturas inferiores a $150{ }^{\circ} \mathrm{C}$, objeto deste trabalho, um dispositivo semelhante é utilizado, com metodologia também semelhante. 


\subsection{Modelo teórico para medição da emissividade}

No modelo adotado para este trabalho iremos fazer a calibração de um medidor de emissividade através da medição das temperaturas em seis pontos do experimento. Nestes pontos foram instalados termopares em pares para que seja medida a variação de temperatura entre os locais.(Esta configuração será mostrada detalhadamente no capítulo 3 deste trabalho.) Desta maneira podemos calcular a transferência de calor no espaço anular desejado. Para que a medição seja feita de maneira satisfatória, algumas hipóteses serão utilizadas para essa modelagem:

- Transferência de calor apenas na direção radial

- Fluxo constante

- Convecção e radiação como meio de troca de calor

A perda de calor na direção longitudinal será reduzida com o uso de isolantes térmicos nas extremidades, alem da geometria utilizada que favorece a minimização desta perda.

A segunda hipótese de fluxo constante também será garantida com o uso de banho térmico e controle/monitoramento da corrente passante na resistência térmica usada como fonte de calor.

De acordo com [2] , o calor trocado entre as superfícies no espaço anular é dado pela seguinte equação:

$$
q=\frac{A_{1}\left(E_{b 1}-E_{b 2}\right)}{\frac{1}{\varepsilon_{1}}+\frac{A_{1}}{A_{2}}\left(\frac{1}{\varepsilon_{2}}-1\right)}
$$


Onde as emissividades $\varepsilon_{1}$ e $\varepsilon_{2}$ são iguais pelo uso do mesmo material e aplicação de uma tinta idêntica nas duas superfícies.(Os materiais adotados serão descritos no capítulo 3 deste trabalho).

Abaixo segue uma figura esquemática mostrando o experimento e as variáveis de ( 4 ).

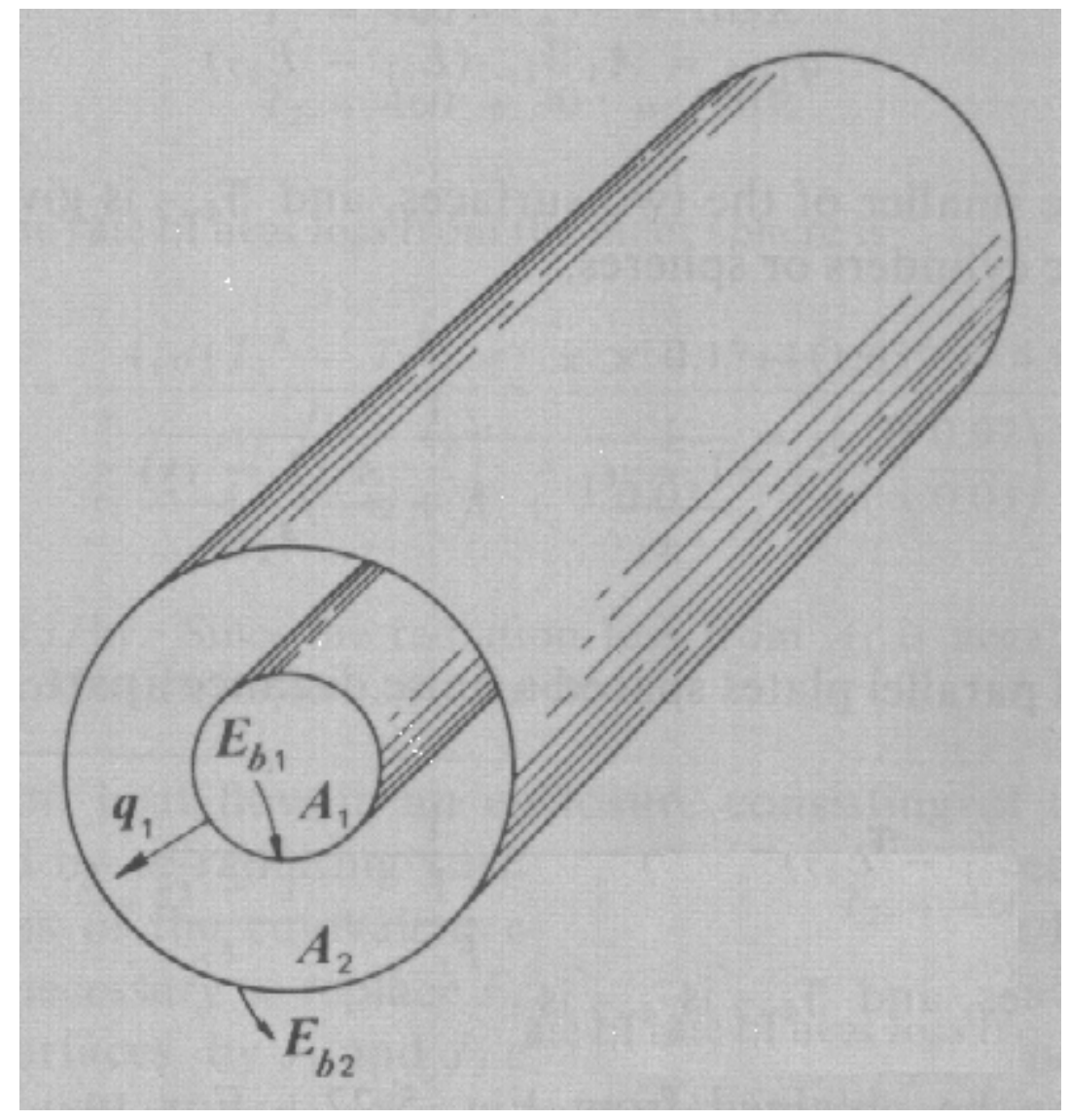

Figura 4 - Desenho esquemático de acordo com ( 4 ) 


\section{PROCEDIMENTO EXPERIMENTAL}

\subsection{Descrição}

O modelo estudado neste trabalho consiste basicamente de dois tubos de latão com diâmetros de $\mathrm{D}_{1}=21 \mathrm{~mm}$ e $\mathrm{D}_{2}=52 \mathrm{~mm}$ e altura igual à $\mathrm{L}=147 \mathrm{~mm}$. Estes tubos foram soldados em suas extremidades a duas bases de mesmo material de maneira que fossem posicionados cocêntricamente. Em uma das extremidades foi instalado um sistema para ser feito o vácuo no espaço anular. Este sistema é composto de um válvula de retenção, adaptadores para fixação de tubo de polietileno e dois metros de tubo de polietileno de diâmetro igual à $1 / 8$ ".

Com o conjunto devidamente montado, foram instalados seis termopares do tipo " $T$ " da marca Omega que irão medir em canais independentes a temperatura.Os sensores de temperatura estão dispostos da seguinte maneira:

- Três na superfície interna do tubo interno

- Três na superfície externa do tubo externo

A intenção da instalação dos termopares é poder através da medição das temperaturas, obter o fluxo de calor no espaço anular.O posicionamento detalhado dos termopares segue no desenho esquemático abaixo: 


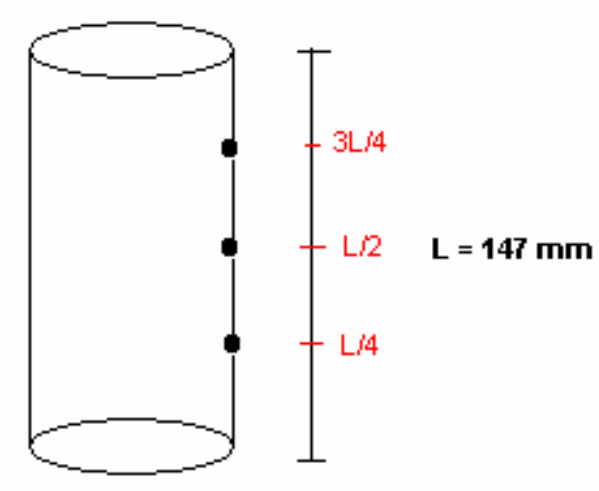

Figura 5 - Posição dos termopares nos tubos

Termopar é um instrumento para medição de temperatura que se baseia na força eletromotriz gerada em um circuito aberto formado por dois materiais distintos e com junções em temperaturas diferentes. Essa força eletromotriz recebe o nome de voltagem Seebeck $\left({ }^{E}\right)$. Essa voltagem varia de acordo com os materiais que formam o par e com a diferença de temperatura das junções através do coeficiente de Seebeck ${ }^{\alpha_{A B}}$, da seguinte forma:

$$
d E_{s}=\alpha_{A B} d T
$$

O coeficiente de Seebeck pode ser obtido através da calibração do termopar. Uma maneira de realizar esta calibração é conforme mostrado na Figura 1. A figura mostra a ligação de dois termopares (TP1 e TP2) ligados a um banho termostático e de um terceiro termopar ( $R E F)$ ligado a uma referência (banho de gelo). 


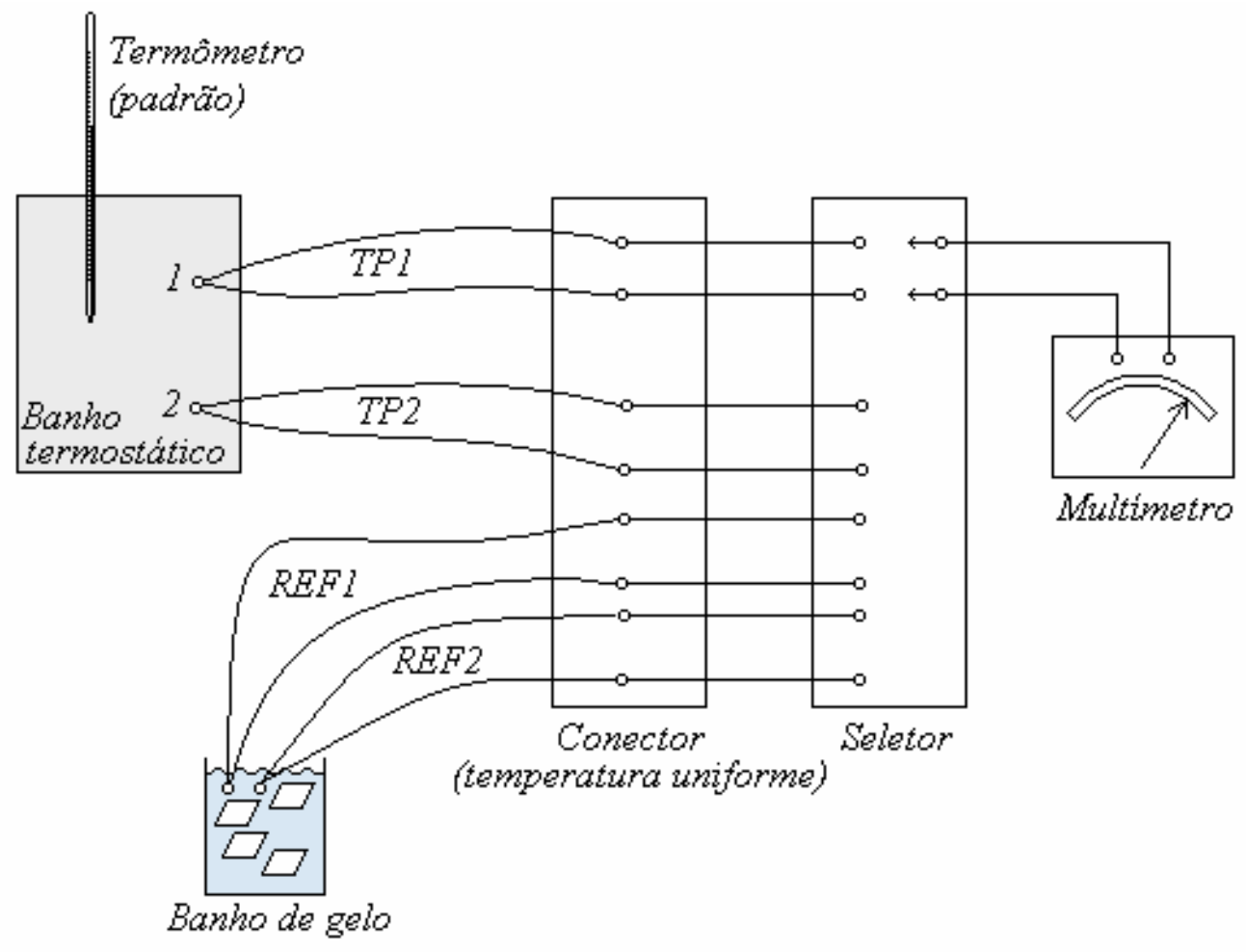

Figura 6 - Esquema de medição dos termopares

Para cada temperatura do banho termostático, pode-se medir a voltagem correspondente no termopar. Para isso, deve-se medir a voltagem entre o banho termostático e o conector $(T P 1$ ou $T P 2)$ e subtrair dela a voltagem medida entre a referência e o conector ( $R E F 1$ ou $R E F 2)$. Variando-se a temperatura do banho, pode-se, então, traçar uma curva que relaciona temperatura do padrão com a voltagem no termopar. Esta curva pode ser aproximada por uma equação do tipo:

$$
T=a E+b
$$

onde $E$ é a voltagem gerada no termopar quando submetido a uma diferença e temperatura $T$. O coeficiente $a$ é o próprio coeficiente de Seebeck. 
Para que fossem feitas as medidas nos termopares utilizamos uma chave seletora de seis canais da marca Engpro, com o objetivo de selecionar um dos termopares a ser avaliado. Estes canais por sua vez, foram ligados a um multímetro digital da marca FLUKE, modelo 8050A que irá mostrar a voltagem medida em cada um dos termopares. A resolução do multímetro é de $0,01 \mathrm{mV}$,com uma faixa de medição variando entre $10^{-2}$ e $10^{4}$.

Será também utilizado um banho de gelo como referencia na temperatura de $0^{\circ} \mathrm{C}$ para termos uma base eficiente de medições, desprezando influencias das variações da temperatura ambiente.

O calor fornecido ao experimento será gerado através do uso de duas resistências elétricas de valores de 50 e 88 ohms. Estas resistências são ligadas independentes ou em paralelo de forma a gerar a temperatura necessária para as medições. As temperaturas utilizadas para a medição serão: $\mathrm{T} 1=60^{\circ} \mathrm{C} ; \mathrm{T} 2=90^{\circ} \mathrm{C} ; \mathrm{T} 3=150^{\circ} \mathrm{C}$;

A fim de garantirmos todas as hipóteses levantadas na seção 2.3 deste trabalho iremos utilizar dois pedaços de lã de vidro de espessura.......de maneira que possamos isolar termicamente as extremidades dos cilindros. Deste modo iremos admitir uma troca de calor apenas no sentido radial.

O processo de medição se inicia com a geração de calor por parte das resistências, tendo que ser monitorada as variações de temperatura que estão ocorrendo para acharmos um tempo de equilíbrio onde o calor gerado está convergindo a um valor desejado, de modo que possamos desprezar as parcelas de troca de calor em regime transiente.Com as temperaturas estabilizadas efetuamos as medições de temperatura nos seis termopares e através de (4) obtemos o fluxo de calor no espaço anular. 


\subsection{Cálculo das Incertezas}

As incertezas que iremos analisar são, em sua maioria, similares a [1] devido a sua geometria e seus componentes de uma forma em geral:

Os parâmetros que devemos analisar para compor uma boa análise de incerteza são:

- Geometria

- Diâmetro

- Altura

- Instrumentos

- Termopares

- Multímetro

- Temperatura

- Tensão

- Resistividade

- Incertezas associadas à medição

Desta maneira, podemos basicamente dizer que a incerteza associada ao experimento é:

$$
\begin{aligned}
& \left(\Delta E^{2}\right)=\left(\frac{\partial E}{\partial A_{1}} \cdot \Delta A_{1}\right)^{2}+\left(\frac{\partial E}{\partial A_{2}} \cdot \Delta A_{2}\right)^{2}+\left(\frac{\partial E}{\partial T_{1}} \cdot \Delta T_{1}\right)^{2}+\left(\frac{\partial E}{\partial A_{2}} \cdot \Delta T_{2}\right)^{2}+\left(\frac{\partial E}{\partial Q} \cdot \Delta Q\right)^{2}+ \\
& \left(\frac{\partial E}{\partial V} \cdot \Delta V\right)^{2}+\left(\frac{\partial E}{\partial R} \cdot \Delta R\right)^{2}
\end{aligned}
$$

Para todas as medidas iremos adotar as resoluções dos equipamentos utilizados ou o percentual de incerteza associado ao equipamento fornecido pelo pelo fabricante ou, ainda, os resultados obtidos em [1] devido sua similaridade, tendo assim temos: 


$$
\begin{aligned}
& U_{d 1}= \pm 0,01 \mathrm{~mm} \\
& U_{d 2}= \pm 0,01 \mathrm{~mm} \\
& U_{h}= \pm 0,01 \mathrm{~mm} \\
& U_{T 1}= \pm 8 \mathrm{~K} \\
& U_{T 2}= \pm 8 \mathrm{~K} \\
& U_{V}= \pm 0,001 \mathrm{mV} \\
& U_{R}= \pm 0,001 \mathrm{~m} \Omega
\end{aligned}
$$

Para a emissividade, o valor encontrado utilizando o termovisor é:

$$
\varepsilon=0,95 \pm 0,02
$$

Desta maneira o procedimento a ser adotado é fazer o calculo das incertezas associadas à metodologia aplicada para o cálculo das potências e assim chegar na incerteza do coeficiente de transferência de calor para convecção, permitindo a calibração do aparato para medição da emissividade.

Para a potência associada à radiação temos:

$$
\left(\frac{U_{Q r}}{q_{r}}\right)^{2}=\left(\frac{\partial Q r}{\partial A_{1}} \cdot U A_{1}\right)^{2}+\left(\frac{\partial Q r}{\partial T_{1}} \cdot U T_{1}\right)^{2}+\left(\frac{\partial Q r}{\partial A_{2}} \cdot U A_{2}\right)^{2}+\left(\frac{\partial Q r}{\partial T_{2}} \cdot U T_{2}\right)^{2}+\left(\frac{\partial Q r}{\partial \varepsilon} \cdot U \varepsilon\right)^{2}
$$

Onde:

$$
\left(\frac{U_{A 1}}{A_{1}}\right)^{2}=\left(\frac{U_{D 1}}{D_{1}}\right)^{2}+\left(\frac{U_{h}}{h}\right)^{2} \text { e }\left(\frac{U_{A 2}}{A_{2}}\right)^{2}=\left(\frac{U_{D 2}}{D_{2}}\right)^{2}+\left(\frac{U_{h}}{h}\right)^{2}
$$

Logo

$$
U_{Q r}=, \quad \begin{array}{|c|c|c|}
\hline 88 \text { Ohms } & 50 \text { Ohms } & 34 \text { Ohms } \\
\hline 0,174 & 0,327 & 0,905 \\
\hline
\end{array}
$$


A incerteza associada à potência gerada no aparato via resistência é:

$$
\left(\frac{U_{\text {Qres }}}{q_{\text {res }}}\right)^{2}=4 \cdot\left(\frac{\partial V}{\partial V} \cdot U_{V}\right)^{2}+\left(\frac{\partial R}{\partial R} \cdot U_{R}\right)^{2}
$$

Logo ,

$$
U_{\text {Qres }}=\begin{array}{|c|c|c|}
\hline 88 \text { Ohms } & 50 \text { Ohms } & 34 \text { Ohms } \\
\hline 0,005 & 0,010 & 0,010 \\
\hline
\end{array}
$$

Assim podemos facilmente obter a expressão da incerteza devido à transferência de calor associada a convecção:

$$
U_{c}^{2}=U_{Q r}^{2}+U_{Q r e s}^{2}
$$

Logo,

$U_{c}=\quad$\begin{tabular}{|c|c|c|}
\hline 88 Ohms & 50 Ohms & 34 Ohms \\
\hline 0,174 & 0,327 & 0,906 \\
\hline
\end{tabular}

Podemos perceber que as incertezas associadas à potência gerada, praticamente não alteram o resultado das incertezas. 


\section{RESULTADOS}

\subsection{Tabelas}

4.1.1 Medições de temperatura e cálculos para a resistência de $88 \Omega$ :

\begin{tabular}{|c|c|c|c|c|c|c|}
\hline $\mathrm{T} 01$ & $\mathrm{~T} 02$ & $\mathrm{~T} 03$ & $\mathrm{~T} 04$ & $\mathrm{~T} 05$ & $\mathrm{~T} 06$ & $\mathrm{Tamb}$ \\
\hline $\mathrm{mV}$ & $\mathrm{mV}$ & $\mathrm{mV}$ & $\mathrm{mV}$ & $\mathrm{mV}$ & $\mathrm{mV}$ & ${ }^{\circ} \mathrm{C}$ \\
\hline & & & & & & \\
\hline 1,8716 & 1,8491 & 1,8376 & 2,1246 & 3,0912 & 2,1124 & 25,0 \\
\hline 1,8693 & 1,8468 & 1,8349 & 2,1251 & 3,0912 & 2,1101 & 25,0 \\
\hline 1,8740 & 1,8514 & 1,8397 & 2,1290 & 3,0998 & 2,1139 & 25,0 \\
\hline 1,8774 & 1,8535 & 1,8384 & 2,1330 & 3,1014 & 2,1161 & 25,0 \\
\hline 1,8807 & 1,8556 & 1,8416 & 2,1342 & 3,1027 & 2,1185 & 25,0 \\
\hline 1,8840 & 1,8605 & 1,8499 & 2,1385 & 3,1065 & 2,1230 & 25,0 \\
\hline
\end{tabular}

Tabela 3 - Medidas obtidas nos termopares e a temperatura ambiente no momento para 0 caso da resistência de $88 \Omega$.

\begin{tabular}{|c|c|c|c|c|c|c|c|c|c|}
\hline $\mathrm{T} 01$ & $\mathrm{~T} 02$ & $\mathrm{~T} 03$ & Média & $\mathrm{U}$ & $\mathrm{T} 04$ & $\mathrm{~T} 05$ & $\mathrm{~T} 06$ & Média & $\mathrm{U}$ \\
\hline${ }^{\circ} \mathrm{C}$ & ${ }^{\circ} \mathrm{C}$ & ${ }^{\circ} \mathrm{C}$ & $\mathrm{K}$ & $\mathrm{K}$ & ${ }^{\circ} \mathrm{C}$ & ${ }^{\circ} \mathrm{C}$ & ${ }^{\circ} \mathrm{C}$ & $\mathrm{K}$ & $\mathrm{K}$ \\
\hline & & & & & & & & & \\
\hline 46,16 & 45,63 & 45,36 & 318,87 & 1,85 & 52,08 & 74,10 & 51,80 & 325,09 & 2,8 \\
\hline 46,11 & 45,58 & 45,30 & 318,81 & 1,86 & 52,10 & 74,10 & 51,75 & 325,07 & 3,4 \\
\hline 46,22 & 45,69 & 45,41 & 318,92 & 1,86 & 52,19 & 74,29 & 51,84 & 325,16 & 3,5 \\
\hline 46,30 & 45,74 & 45,38 & 318,96 & 2,10 & 52,28 & 74,33 & 51,89 & 325,23 & 3,9 \\
\hline 46,38 & 45,79 & 45,46 & 319,02 & 2,11 & 52,31 & 74,36 & 51,94 & 325,28 & 3,6 \\
\hline 46,46 & 45,90 & 45,65 & 319,15 & 1,86 & 52,41 & 74,44 & 52,05 & 325,38 & 3,6 \\
\hline
\end{tabular}

Tabela 4 - As medidas dos termopares convertidas para temperaturas, as médias e o desvio padrão associado para o caso da resistência de $88 \Omega$.

\begin{tabular}{|c|c|c|c|c|c|}
\hline $\mathrm{V}$ & $\mathrm{R}$ & $\mathrm{Q}_{\mathrm{res}}$ & $\mathrm{F}(\varepsilon)$ & Qconv & haA \\
\hline $\mathrm{V}$ & $\Omega$ & $\mathrm{W}$ & - & $\mathrm{W}$ & $\mathrm{W} / \mathrm{K}$ \\
\hline & & & & & \\
\hline 4,50 & 3,80 & 5,33 & 1,07 & 4,90 & 0,79 \\
\hline 4,50 & 3,80 & 5,33 & 1,07 & 4,90 & 0,78 \\
\hline 4,50 & 3,80 & 5,33 & 1,07 & 4,90 & 0,79 \\
\hline 4,50 & 3,80 & 5,33 & 1,07 & 4,90 & 0,78 \\
\hline 4,50 & 3,80 & 5,33 & 1,07 & 4,90 & 0,78 \\
\hline 4,50 & 3,80 & 5,33 & 1,07 & 4,90 & 0,79 \\
\hline
\end{tabular}

Tabela 5 - Cálculo das Potências e o valor do coeficiente de transferência para o caso da resistência de $88 \Omega$. 
4.1.2 Medições de temperatura e cálculos para a resistência de $50 \Omega$ :

\begin{tabular}{|c|c|c|c|c|c|c|}
\hline T01 & T02 & T03 & T04 & T05 & T06 & Tamb \\
\hline $\mathrm{mV}$ & $\mathrm{mV}$ & $\mathrm{mV}$ & $\mathrm{mV}$ & $\mathrm{mV}$ & $\mathrm{mV}$ & ${ }^{\circ} \mathrm{C}$ \\
\hline & & & & & & \\
\hline 3,2829 & 3,2045 & 3,1517 & 4,0302 & 6,9092 & 3,9260 & 24,0 \\
\hline 3,2848 & 3,2079 & 3,1553 & 4,0355 & 6,9168 & 3,9312 & 24,0 \\
\hline 3,2882 & 3,2115 & 3,1639 & 4,0353 & 6,8891 & 3,9290 & 24,0 \\
\hline 3,2857 & 3,2098 & 3,1598 & 4,0335 & 6,8759 & 3,9265 & 24,0 \\
\hline 3,2860 & 3,2092 & 3,1619 & 4,0324 & 6,8701 & 3,9237 & 24,0 \\
\hline 3,2829 & 3,2035 & 3,1600 & 4,0276 & 6,8643 & 3,9199 & 24,0 \\
\hline
\end{tabular}

Tabela 6 - Medidas obtidas nos termopares e a temperatura ambiente no momento para o caso da resistência de $50 \Omega$.

\begin{tabular}{|c|c|c|c|c|c|c|c|c|c|}
\hline T01 & T02 & T03 & Média & $\mathrm{U}$ & $\mathrm{T} 04$ & $\mathrm{~T} 05$ & $\mathrm{~T} 06$ & Média & $\mathrm{U}$ \\
\hline${ }^{\circ} \mathrm{C}$ & ${ }^{\circ} \mathrm{C}$ & ${ }^{\circ} \mathrm{C}$ & $\mathrm{K}$ & $\mathrm{K}$ & ${ }^{\circ} \mathrm{C}$ & ${ }^{\circ} \mathrm{C}$ & ${ }^{\circ} \mathrm{C}$ & $\mathrm{K}$ & $\mathrm{K}$ \\
\hline & & & & & & & & & \\
\hline 78,37 & 76,63 & 75,45 & 349,96 & 6,64 & 94,69 & 154,11 & 92,44 & 366,72 & 22,2 \\
\hline 78,41 & 76,70 & 75,53 & 350,03 & 6,55 & 94,81 & 154,26 & 92,56 & 366,83 & 22,2 \\
\hline 78,48 & 76,78 & 75,72 & 350,15 & 6,31 & 94,80 & 153,71 & 92,51 & 366,81 & 22,7 \\
\hline 78,43 & 76,74 & 75,63 & 350,08 & 6,38 & 94,77 & 153,45 & 92,45 & 366,76 & 22,8 \\
\hline 78,43 & 76,73 & 75,68 & 350,10 & 6,30 & 94,74 & 153,34 & 92,39 & 366,72 & 23,2 \\
\hline 78,37 & 76,60 & 75,64 & 350,02 & 6,27 & 94,64 & 153,22 & 92,31 & 366,62 & 23,0 \\
\hline
\end{tabular}

Tabela 7 - As medidas dos termopares convertidas para temperaturas, as médias e o desvio padrão associado para o caso da resistência de $50 \Omega$.

\begin{tabular}{|c|c|c|c|c|c|c|}
\hline $\mathrm{V}$ & $\mathrm{R}$ & $\mathrm{Pot}=\mathrm{Q}$ & $\mathrm{F}(\varepsilon)$ & $\mathrm{Qr}$ & $\mathrm{Qc}$ & haA \\
\hline $\mathrm{V}$ & $\Omega$ & $\mathrm{W}$ & - & $\mathrm{W}$ & $\mathrm{W}$ & W/K \\
\hline & & & & & & \\
\hline 8,20 & 3,80 & 17,69 & 1,07 & 1,58 & 16,12 & 0,962 \\
\hline 8,20 & 3,80 & 17,69 & 1,07 & 1,59 & 16,11 & 0,959 \\
\hline 8,20 & 3,80 & 17,69 & 1,07 & 1,57 & 16,12 & 0,968 \\
\hline 8,20 & 3,80 & 17,69 & 1,07 & 1,57 & 16,12 & 0,967 \\
\hline 8,20 & 3,80 & 17,69 & 1,07 & 1,57 & 16,13 & 0,970 \\
\hline 8,20 & 3,80 & 17,69 & 1,07 & 1,57 & 16,13 & 0,971 \\
\hline
\end{tabular}

Tabela 8 - Cálculo das Potências e o valor do coeficiente de transferência para o caso da resistência de $50 \Omega$. 
4.1.3 Medições de temperatura e cálculos para a resistência de $50 \Omega$ e $80 \Omega$ ligadas em paralelo:

\begin{tabular}{|c|c|c|c|c|c|c|}
\hline $\mathrm{T} 01$ & $\mathrm{~T} 02$ & $\mathrm{~T} 03$ & $\mathrm{~T} 04$ & $\mathrm{~T} 05$ & $\mathrm{~T} 06$ & $\mathrm{Tamb}$ \\
\hline $\mathrm{mV}$ & $\mathrm{mV}$ & $\mathrm{mV}$ & $\mathrm{mV}$ & $\mathrm{mV}$ & $\mathrm{mV}$ & ${ }^{\circ} \mathrm{C}$ \\
\hline & & & & & & \\
\hline 5,8629 & 5,6612 & 5,5294 & 7,5857 & 12,5212 & 7,3206 & 25,0 \\
\hline 5,8728 & 5,6696 & 5,5091 & 7,6016 & 12,5170 & 7,3378 & 25,0 \\
\hline 5,8822 & 5,6809 & 5,5267 & 7,6119 & 12,5100 & 7,3488 & 25,0 \\
\hline 5,8906 & 5,6825 & 5,5239 & 7,6219 & 12,4923 & 7,3550 & 25,0 \\
\hline 5,8870 & 5,6826 & 5,5233 & 7,6122 & 12,4385 & 7,3560 & 25,0 \\
\hline 5,8898 & 5,6860 & 5,5382 & 7,6137 & 12,4194 & 7,3560 & 25,0 \\
\hline
\end{tabular}

Tabela 9 - Medidas obtidas nos termopares e a temperatura ambiente no momento para 0 caso das resistências de $50 \Omega$ e de $80 \Omega$ ligadas em paralelo.

\begin{tabular}{|c|c|c|c|c|c|c|c|c|c|}
\hline T01 & T02 & T03 & Média & $\mathrm{U}$ & $\mathrm{T} 04$ & $\mathrm{~T} 05$ & $\mathrm{~T} 06$ & Média & $\mathrm{U}$ \\
\hline${ }^{\circ} \mathrm{C}$ & ${ }^{\circ} \mathrm{C}$ & ${ }^{\circ} \mathrm{C}$ & $\mathrm{K}$ & $\mathrm{K}$ & ${ }^{\circ} \mathrm{C}$ & ${ }^{\circ} \mathrm{C}$ & ${ }^{\circ} \mathrm{C}$ & $\mathrm{K}$ & $\mathrm{K}$ \\
\hline & & & & & & & & & \\
\hline 133,08 & 128,95 & 126,25 & 402,58 & 15,58 & 167,43 & 259,10 & 162,23 & 437,98 & 51,3 \\
\hline 133,28 & 129,13 & 125,83 & 402,56 & 16,91 & 167,74 & 259,03 & 162,57 & 438,30 & 51,0 \\
\hline 133,47 & 129,36 & 126,19 & 402,82 & 16,53 & 167,94 & 258,90 & 162,79 & 438,51 & 50,9 \\
\hline 133,64 & 129,39 & 126,13 & 402,87 & 17,05 & 168,13 & 258,59 & 162,91 & 438,67 & 51,6 \\
\hline 133,57 & 129,39 & 126,12 & 402,84 & 16,91 & 167,94 & 257,63 & 162,93 & 438,59 & 49,5 \\
\hline 133,63 & 129,46 & 126,43 & 402,99 & 16,37 & 167,97 & 257,29 & 162,93 & 438,60 & 49,8 \\
\hline
\end{tabular}

Tabela 10 - As medidas dos termopares convertidas para temperaturas, as médias e o desvio padrão associado para o caso das resistências de $50 \Omega$ e de $80 \Omega$ ligadas em paralelo.

\begin{tabular}{|c|c|c|c|c|c|}
\hline $\mathrm{V}$ & $\mathrm{R}$ & $\mathrm{Pot}=\mathrm{Q}$ & $\mathrm{F}(\varepsilon)$ & $\mathrm{Qc}$ & $\mathrm{haA}$ \\
\hline $\mathrm{V}$ & $\Omega$ & $\mathrm{W}$ & - & $\mathrm{W}$ & $\mathrm{W} / \mathrm{K}$ \\
\hline & & & & & \\
\hline 12,00 & 3,80 & 37,89 & 1,07 & 32,50 & 0,918 \\
\hline 12,00 & 3,80 & 37,89 & 1,07 & 32,45 & 0,908 \\
\hline 12,00 & 3,80 & 37,89 & 1,07 & 32,44 & 0,909 \\
\hline 12,00 & 3,80 & 37,89 & 1,07 & 32,42 & 0,906 \\
\hline 12,00 & 3,80 & 37,89 & 1,07 & 32,43 & 0,907 \\
\hline 12,00 & 3,80 & 37,89 & 1,07 & 32,45 & 0,911 \\
\hline
\end{tabular}

Tabela 11 - Cálculo das Potências e o valor do coeficiente de transferência para o caso das resistências de $50 \Omega$ e de $80 \Omega$ ligadas em paralelo. 


\subsection{Gráficos:}

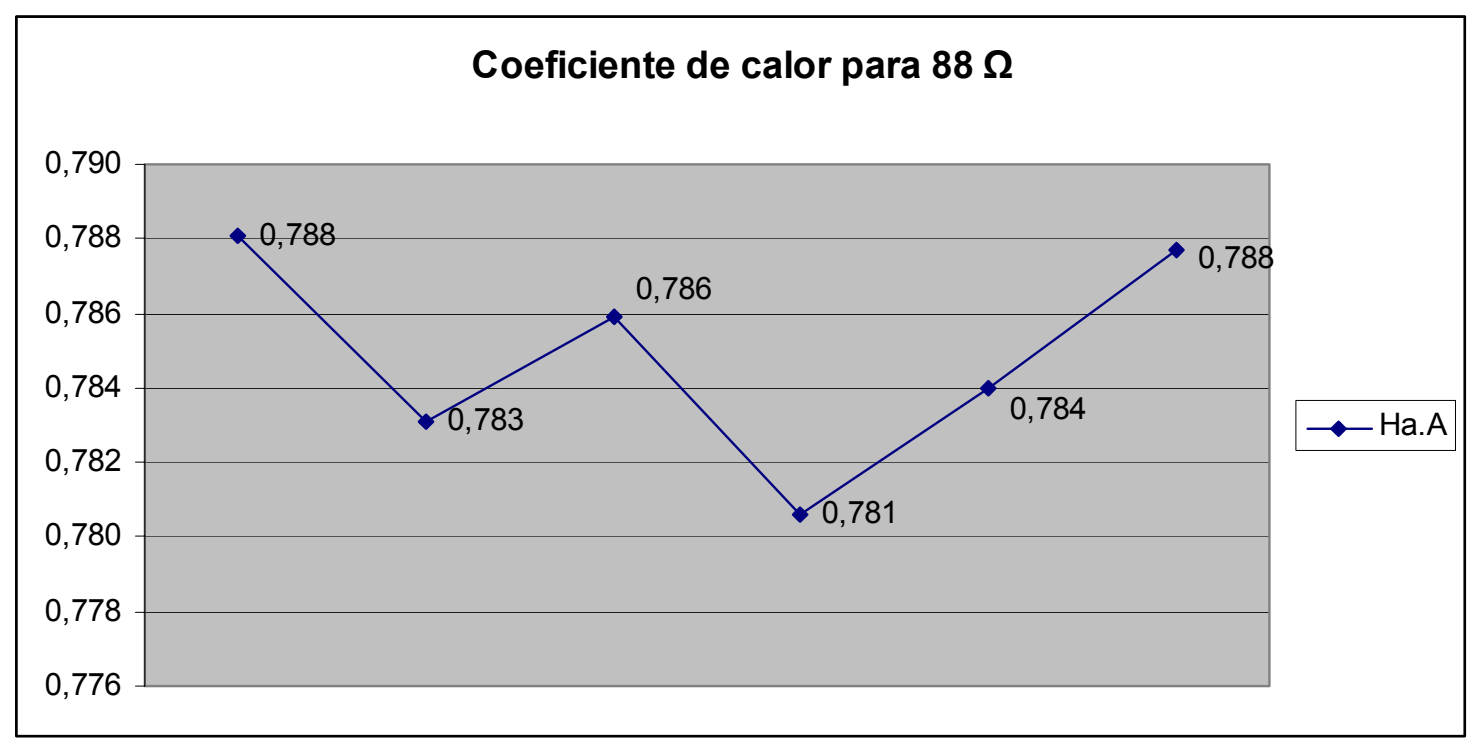

Figura 7 - Gráfico da variação da transferência de calor para $88 \Omega$.

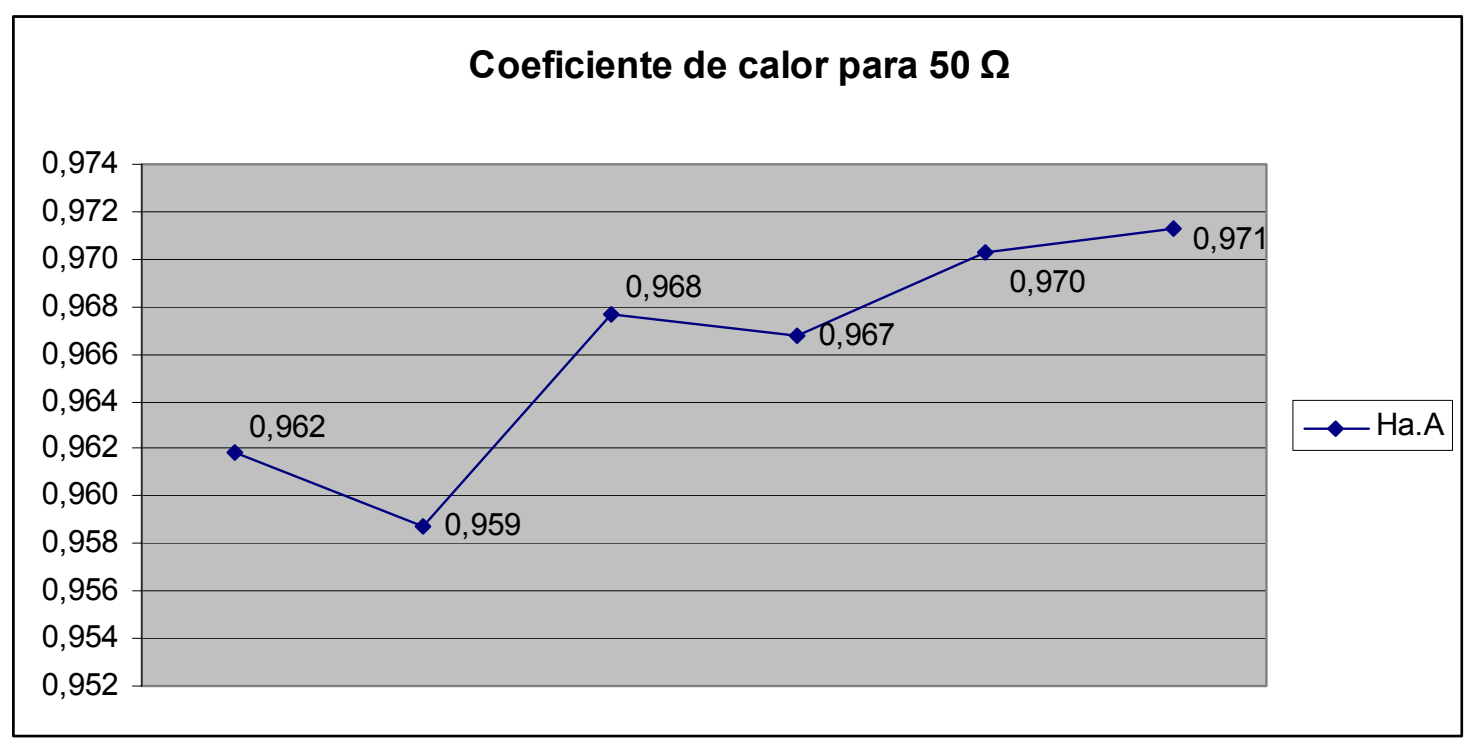

Figura 8 - Gráfico da variação da transferência de calor para $50 \Omega$. 


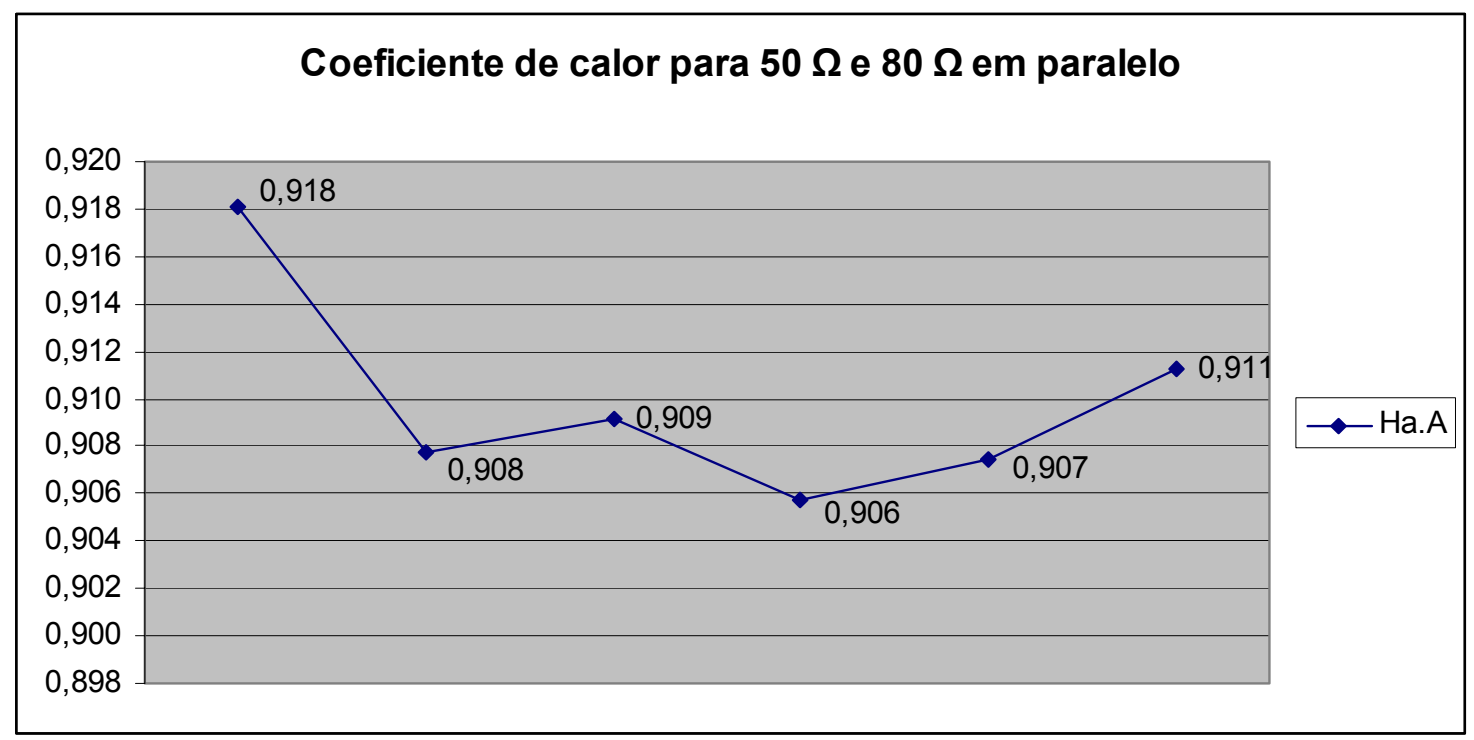

Figura 9 - Gráfico da variação da transferência de calor para $50 \Omega$ e $80 \Omega$ ligados em paralelo. 


\section{CONCLUSÔES}

Foi analisado neste trabalho, a importância do coeficiente de transferência de calor associada à convecção para uma boa determinação das temperaturas feitas por medição remota. Esta importância se dá devido ao percentual de calor trocado devido à radiação e a convecção.

Pode-se verificar também, que o coeficiente de transferência de calor associado à convecção tem maiores variações quando estamos medindo a baixas temperaturas.

Podemos concluir através deste experimento, que as medições feitas remotamente trazem um grande beneficio para as industrias evitando prejuízos com parada de produção e custos elevados de monitoramento com sensores. Esta medição é fácil de ser executada, podendo contribuir ainda mais na busca do melhor desempenho e no controle preditivo ou corretivo. 


\section{BIBLIOGRAFIA}

[1] - Orlando, A.F., Braga, C.V.M. , Braga, S.L. , Determinação Experimental da emisiividade em superfícies, VIII COBEM - S.J. Campos, 1985.

[2] - Principles Of Heat Transfer;Frank Kreith;3rd Edition;1973;Intexl Educational Publishes.

[3] - Pachêco, A. P. Emissividades de superfícies naturais no infravermelho termal . Anais IX Simpósio Brasileiro de Sensoriamento Remoto, INPE, Santos, 1998.

[4] - Incropera, F.P., DeWitt P.D., Fundamentos de transferência de calor e de massa, 4a. Edição, Livros Técnicos e Científicos Editora S.A., 1988.

[5] - Siegel, R. \& Howell, S.R., Thermal Radiation Heat Transfer, McGraw-HillKogakusha Ltd. , N.Y. , 1972. 
ANEXOS

1) Fotos do Experimento:

1.1 Tubos Concêntricos já montados e instrumentados:

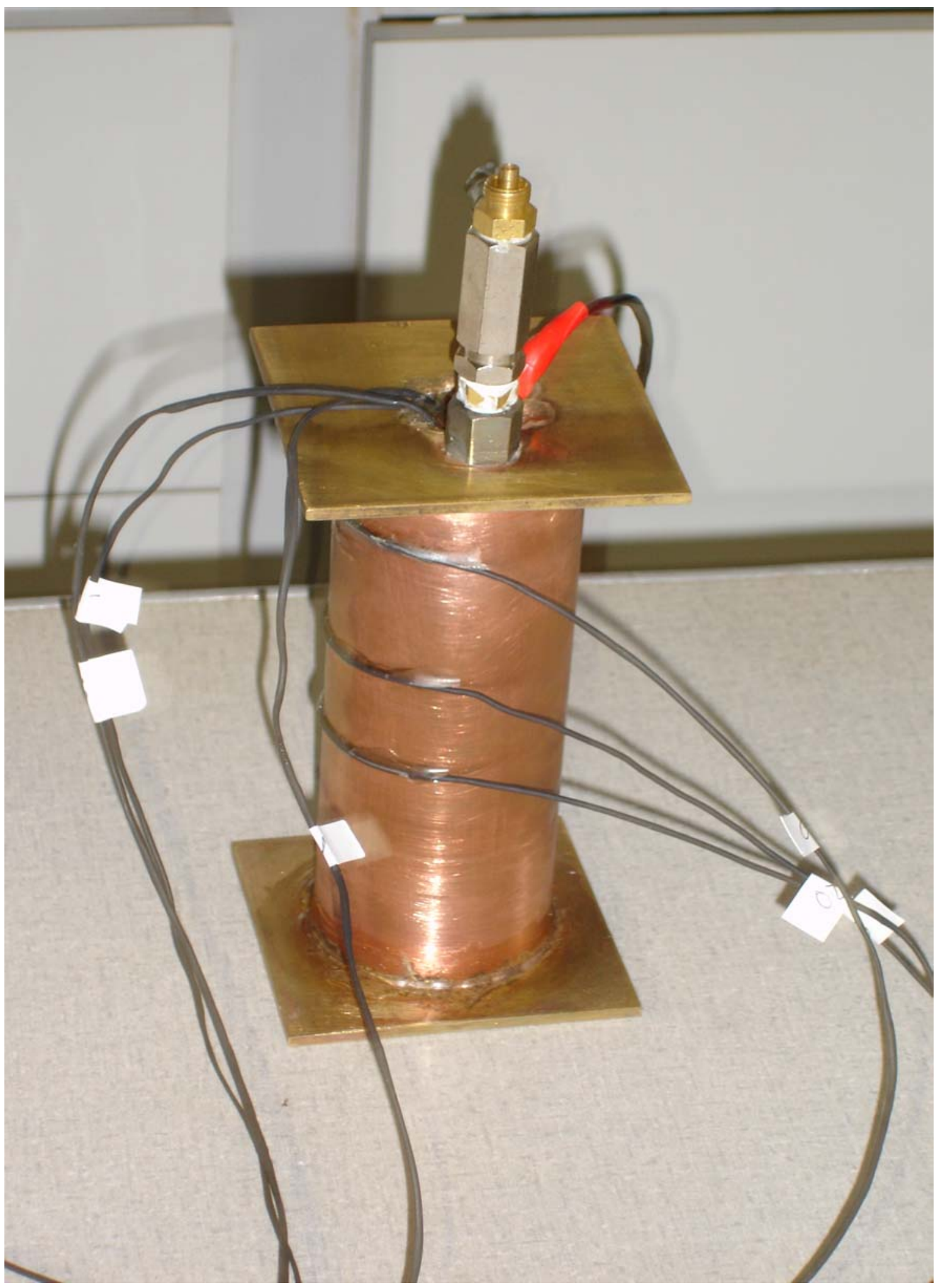




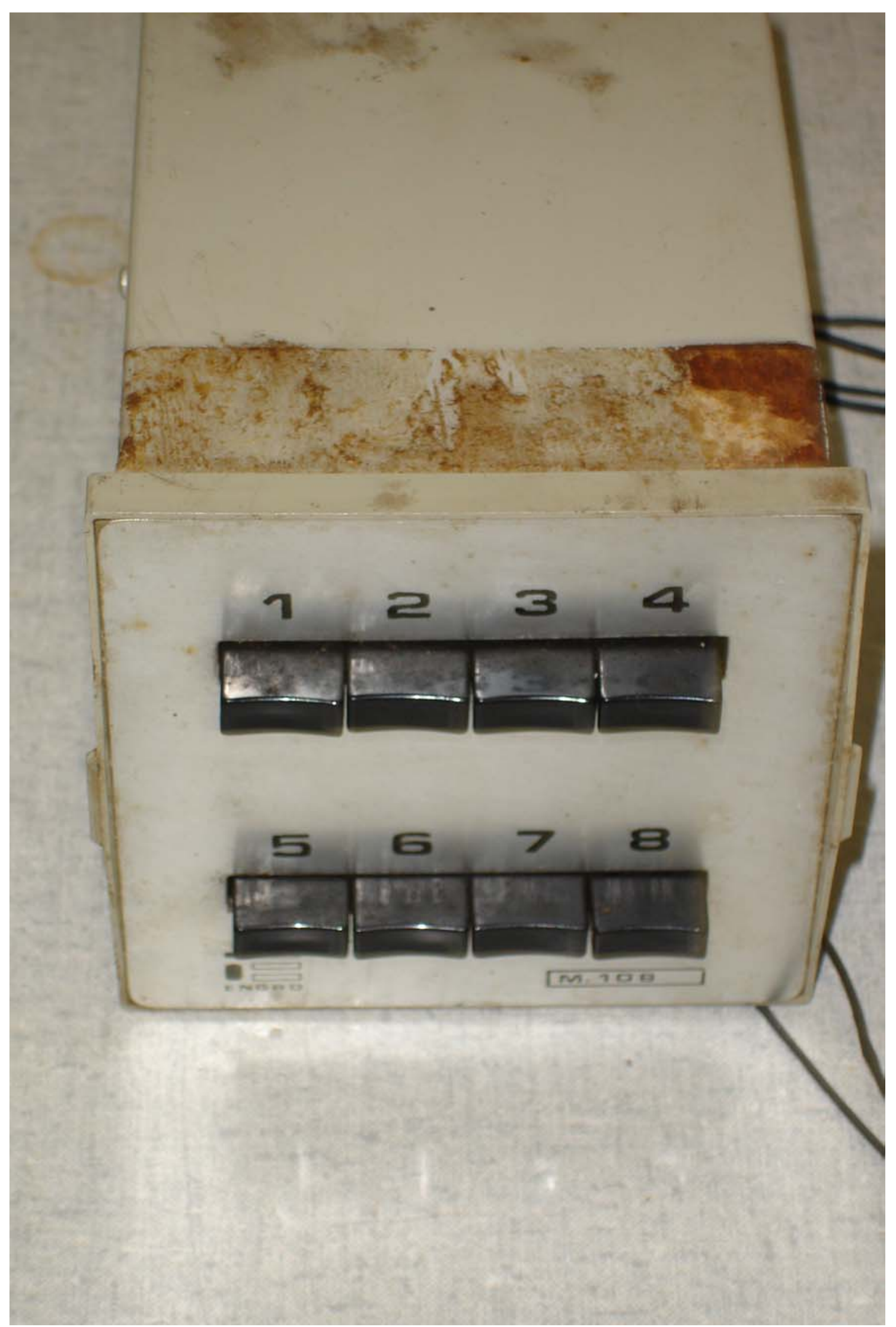




\subsection{Multimetro}

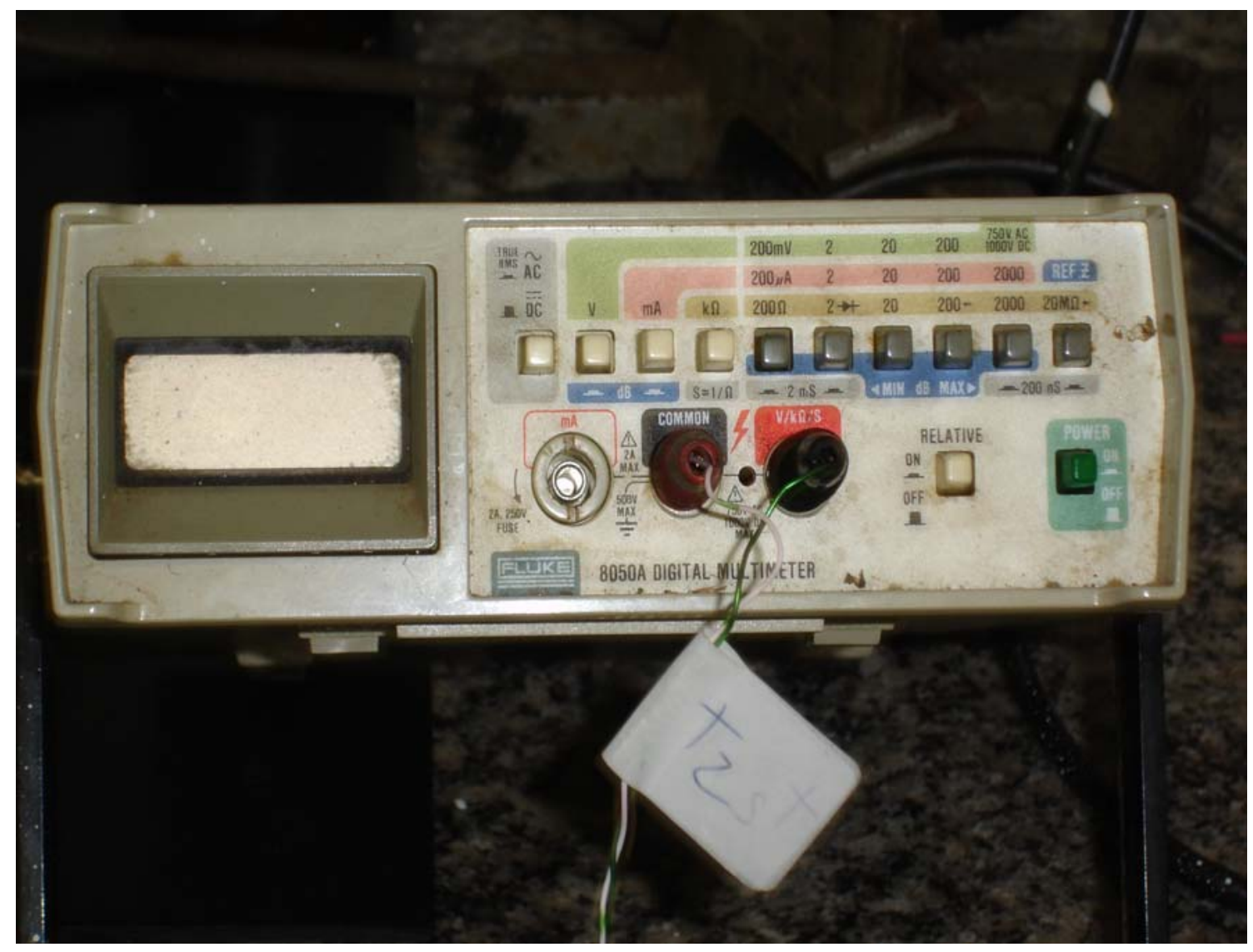




\subsection{Banho de Referencia}

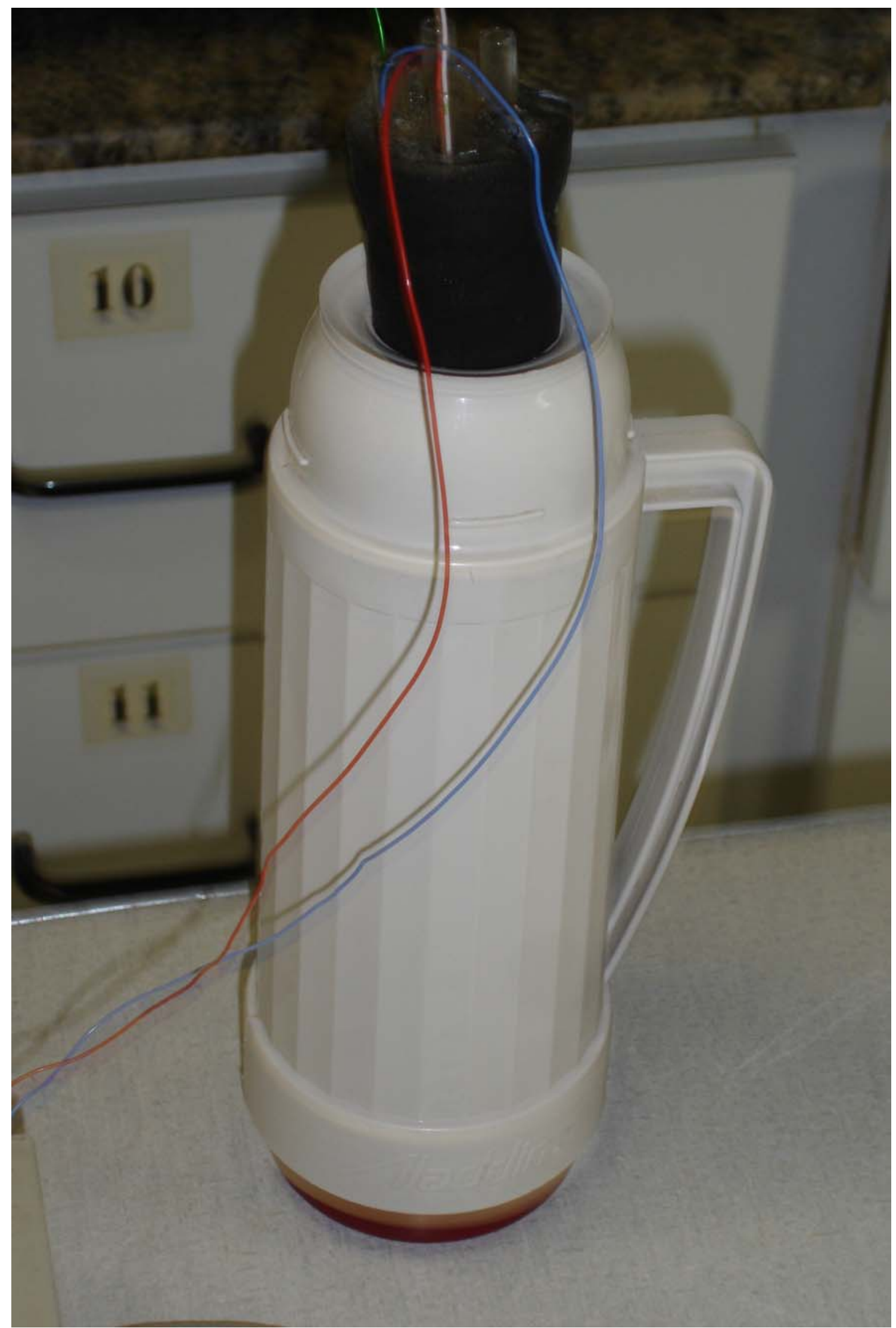


1.5 Resistência responsável pela geração de calor

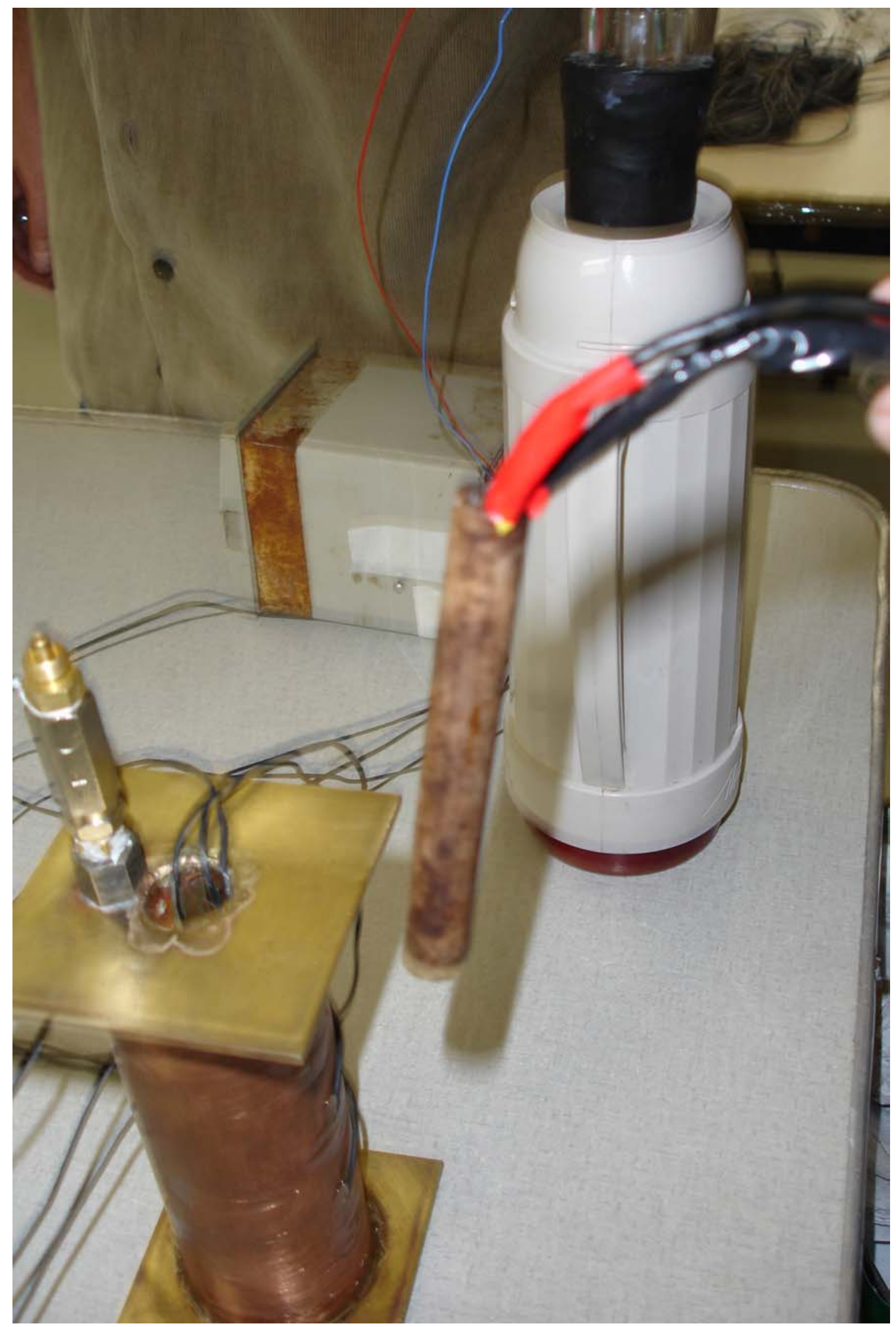


1.6 Experimento Completo

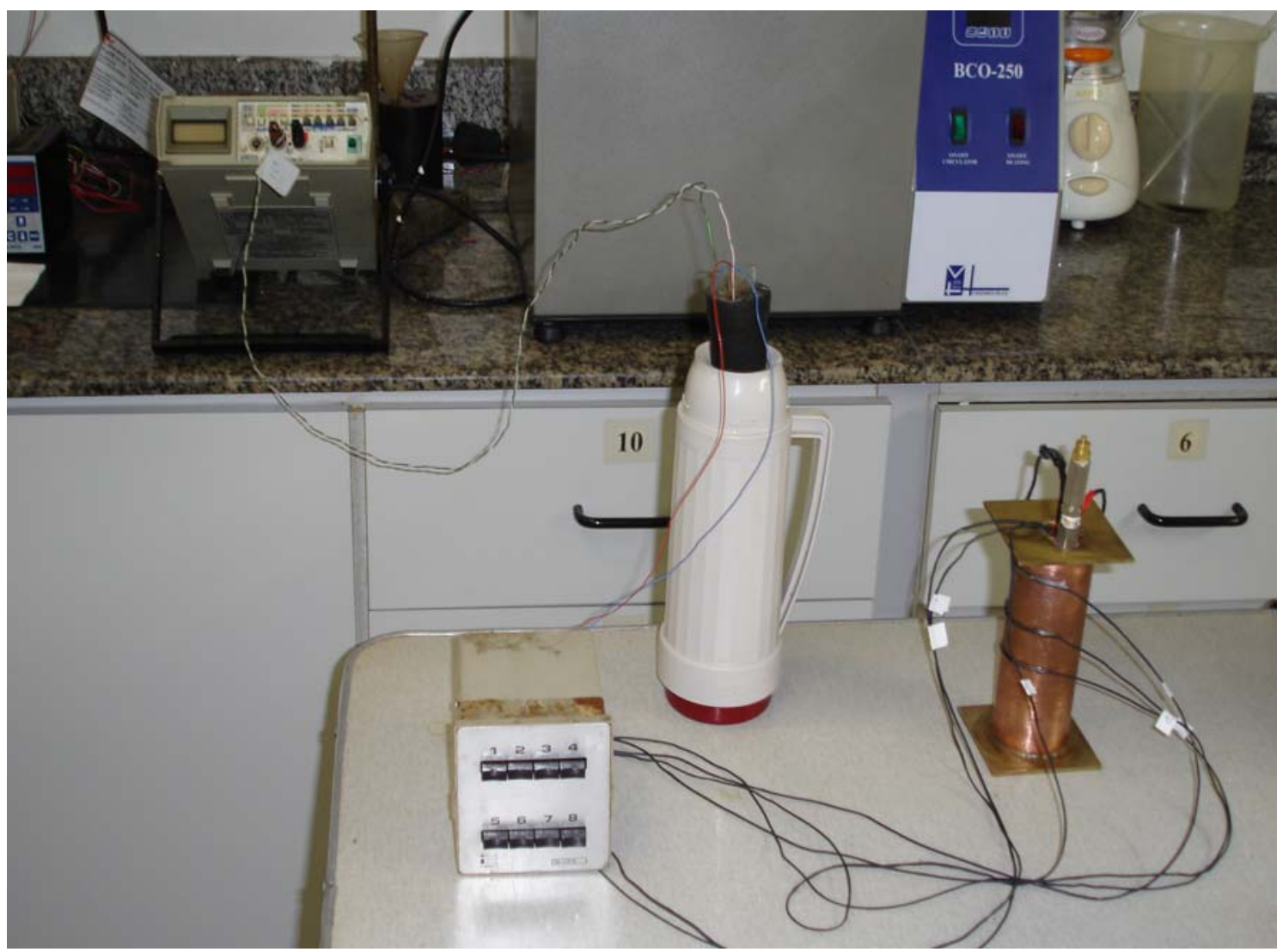

